\title{
Ketamine's pharmacogenomic network in human brain contains sub-networks associated with glutamate neurotransmission and with neuroplasticity
}

One Sentence Summary: The ketamine network in the human brain consists of sub-networks associated with glutamate neurotransmission, neuroplasticity, and pharmacokinetics.

Authors: Gerald A. Higgins ${ }^{1,2}$, Samuel A. Handelman ${ }^{3}$, Ari Allyn-Feuer ${ }^{1} \uparrow$, Alex S. Ade ${ }^{1,2}$, James S. Burns ${ }^{2}$, Gilbert S. Omenn ${ }^{1,3,4,5}$, Brian D. Athey ${ }^{1,2,6 *}$

\section{Affiliations:}

${ }^{1}$ Department of Computational Medicine and Bioinformatics, University of Michigan Medical School, Ann Arbor, MI 48109, USA.

${ }^{2}$ Phenomics Health Inc., Ann Arbor, MI 48109, USA.

${ }^{3}$ Department of Internal Medicine, University of Michigan Medical School, Ann Arbor, MI 48109, USA.

${ }^{4}$ School of Public Health, University of Michigan, Ann Arbor, MI 48109, USA.

${ }^{5}$ Department of Human Genetics, University of Michigan Medical School, Ann Arbor, MI 48109, USA.

${ }^{6}$ Department of Psychiatry, University of Michigan Medical School, Ann Arbor, MI 48109, USA.

*Corresponding author: Email: bleu@med.umich.edu (B.D.A.)

$\dagger$ Current address: GlaxoSmithKline, King of Prussia, PA 19406, USA. 
Abstract: The pharmacogenomic network responsible for the rapid antidepressant action of ketamine and concomitant adverse events in patients has been poorly defined. Integrative, multiscale biological data analytics helps explain ketamine's action. Using a validated computational pipeline, candidate ketamine-response genes and regulatory RNAs from published literature, binding affinity studies, and single nucleotide polymorphisms (SNPs) from genomewide association studies (GWAS), we identified 108 SNPs associated with 110 genes and regulatory RNAs. All of these SNPs are classified as enhancers, and additional chromatin interaction mapping in human neural cell lines and tissue shows enhancer-promoter interactions involving other network members. Pathway analysis and gene set optimization identified three composite sub-networks within the broader ketamine pharmacogenomic network. Expression patterns of ketamine network genes within the postmortem human brain are concordant with ketamine neurocircuitry based on the results of 24 published functional neuroimaging studies. The ketamine pharmacogenomic network is enriched in forebrain regions known to be rapidly activated by ketamine, including cingulate cortex and frontal cortex, and is significantly regulated by ketamine ( $p=6.26 \mathrm{E}-33$; Fisher's exact test). The ketamine pharmacogenomic network can be partitioned into distinct enhancer sub-networks associated with: (1) glutamate neurotransmission, chromatin remodeling, smoking behavior, schizophrenia, pain, nausea, vomiting, and post-operative delirium; (2) neuroplasticity, depression, and alcohol consumption; and (3) pharmacokinetics. The component sub-networks explain the diverse action mechanisms of ketamine and its analogs. These results may be useful for optimizing pharmacotherapy in patients diagnosed with depression, pain or related stress disorders. 


\section{Introduction}

Existing antidepressant medications are not effective for many patients (1). Novel antidepressant drugs include compounds that target the N-methyl-d-aspartate receptor (NMDAR), glycine receptor, or the $\alpha$-amino-3-hydroxy-5-methyl-4-isoxazolepropionic acid receptor (AMPAR) in the human brain. For example, ketamine (RS-2-chlorophenyl-2-methylamino-cyclohexanone), a noncompetitive NMDAR antagonist first approved by the U.S. Food \& Drug Administration (FDA) as a surgical anesthetic in 1970 (2), is being increasingly used to treat refractory depression $(3,4)$. There is evidence that the widespread action of ketamine in the human brain impacts a number of pharmacodynamic targets including AMPARs, cholinergic receptors, calcium channels and other neurotransmitter molecules, although most evidence suggests that ketamine and its analogs exert their actions through partial antagonism of the NMDAR in the human brain (5-8). One presumptive target for ketamine-like drugs is the NMDAR, which also contains binding sites for glycine and D-serine encoded by GLRB, and sites that bind polyamines, histamine, and cations. Neuroimaging studies have demonstrated that intravenous infusion of ketamine causes a transient surge in glutamate levels detected in prefrontal cortex and cingulate cortex in parallel with its rapid antidepressant action $(5,7)$.

A 2018 review provided detailed evidence of the therapeutic mechanisms of ketamine, its enantiomers, and active metabolites (8). Research suggests that ketamine's antidepressant action might result from stimulation of dendritic spine plasticity in the prefrontal cortex $(9)$ or through activation of the inflammasome (10). Ketamine and its metabolites also act as modulators of the opiate, cannabinoid, and related receptors (8), the hyperpolarization activated cyclic nucleotide gated potassium channel (11), the estrogen receptor, and the AMPA receptor subunits GRIA1 and 
GRIA4 (12), and many other known $(8,13)$ and unknown pharmacodynamic targets within human brain. Ketamine and its metabolites strongly induce the expression of the $C Y P 2 B 6$ gene in human brain, which encodes a drug metabolizing enzyme that contributes to first- and second-pass metabolism of the drug and its metabolites (14). Recent genomewide association studies (GWAS) in humans demonstrate association of ketamine response and adverse events with enhancers of genes and long non-coding RNAs (lncRNAs) related to the roundabout guidance receptor 2 (ROBO2) gene, whose product binds members of the slit guidance ligand family (SLIT1, SLIT2) that are involved in dendrite guidance and synaptic plasticity $(15,16)$. Like phencyclidine, a structurally related compound, ketamine induces acute dissociation, with both drugs exhibiting species-specific differences in response. In sum, the central nervous system (CNS) pathway(s) responsible for the rapid antidepressant effects of ketamine and its enantiomers in patients diagnosed with treatment-resistant depression (TRD) remain poorly defined, including emergence of on- and off-target effects and individual differences in response and adverse events.

Problematic adverse events that characterize response to ketamine in humans include acute psychological effects such as dissociation, delirium, and cognitive impairment. The drug's dissociative psychotropic effects have emerged as a mechanism to explain the analgesic, anesthetic and sedative effects of ketamine (1). Both the racemic and enantiomeric formulations of ketamine produce potent and undesirable psychotomimetic adverse events, including acute sensory distortions, derealization, depersonalization, identity confusion, identity alteration, amnesia, hallucinations, anxiety, and fear $(2,5,7,8)$. Dysphoric emergence phenomena occur in a dosedependent manner, while transient phenomena include elevated blood pressure and heart rate, nausea, and vomiting $(6,8)$. 
Intravenous and oral formulations of ketamine have demonstrated efficacy and tolerability in controlled trials and in open-label studies across patient populations known to have little to no response from traditional antidepressants (6-8). The $S$-enantiomer of ketamine (Esketamine; Spravato $^{\mathrm{TM}}$ ) has been approved by the U.S. FDA as a nasal spray to be used in combination with a serotonin reuptake inhibitor-based antidepressant for patients who have been diagnosed with TRD (4). Esketamine has been approved only for administration by a healthcare professional in a clinical setting because it may produce acute adverse events. In sum, ketamine and its analogs are promising therapeutics for patients diagnosed with depression, but it is uncertain how this powerful psychotropic exerts its widespread response and adverse effects in the human brain $(9,10,17-21)$.

Our strategy analyzed disparate data from multiple scales of biological function combining bioinformatics, computational medicine and machine learning (22-25). GWAS SNPs provided insight into the phenotypic consequences of the mutational alterations and variation within disease sub-networks impacted by ketamine, spatial interactions within chromatin that control expression of ketamine-response genes, and mesoscale functional neurocircuits within human brain regions that are rapidly activated following ketamine administration (Figure 1). We hypothesized that the mechanisms of the different on- and off-target effects of ketamine enantiomers could be determined from studies of disease risk and pharmacogenomic variation in the regulatory, noncoding genome or "regulome" $(23,26)$. Most GWAS SNPs are located within enhancers in the three-dimensional (3D) spatial genome and allele-specific open chromatin provides the foundation on which a SNP may impact gene expression and pharmacogenomic variation among humans (2729). This general feature provides a basis for the machine learning algorithms used in this study to determine the putative causal nature of SNPs. If a variant SNP is silenced by heterochromatin 
or is located within euchromatin on an allele shrouded by chromatin, it cannot permit the activation of gene expression by transcription factors. Recent studies demonstrate that the topology of the human genome determines regions of activation and repression of gene transcription and translation, organized into enhancer-promoter and promoter-promoter loops in chromatin and long range interactions mediated by superenhancers, topologically associating domains (TADs), and A and B compartments in chromatin $(30,31)$.

To understand if enhancer networks are active in the same human brain regions where ketamine first exerts a rapid antidepressant response, we determined whether the expressed target genes and their enhancer networks are concentrated within these regions of the CNS. This was accomplished by matching ketamine pharmacogenomic gene expression with higher-order structures where the drug first acts in the human brain, determining whether the GWAS SNPs associated with ketamine's sub-networks act in these CNS regions, and assessing whether enhancer and superenhancer regulatory elements are localized to this circumscribed neuroanatomical substrate

\section{(Figure 1).}




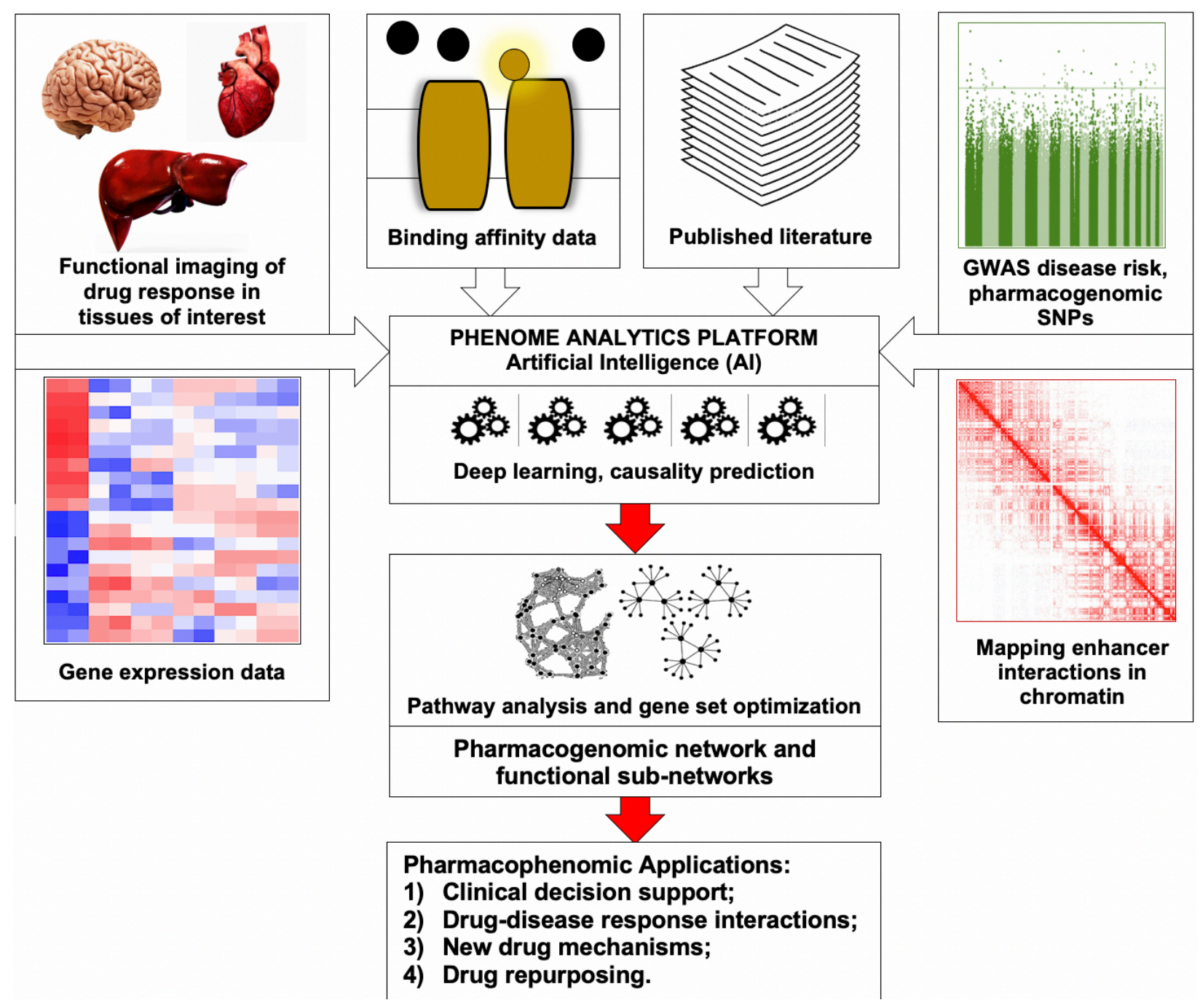

Figure 1. Multi-scale biological data analysis. This strategy for mapping drug networks provides insight into the mechanistic on- and off-target effects, laying a foundation for subsequent preclinical studies. 


\section{Results}

\section{The ketamine pharmacogenomic network in the human brain}

The ketamine pharmacogenomic network we identified consists of 110 genes and regulatory RNAs and exhibits significant overlap with the "cardiovascular disease, neurological disease and organismal injury abnormalities" disease network category as determined using IPA ${ }^{\mathrm{TM}}$ (32) ( $p=1 \mathrm{E}-54$; Fisher's exact test). The proteins encoded by the genes in the network exhibit statistically significant STRING sub-network associations (data not shown) (33). The top 10 most significant biological processes determined by the Panther/Gene Ontology database (34) include trans-synaptic signaling, regulation of membrane potential, behavior, response to drug, and nervous system development. The most significant upstream xenobiotic regulator of the network is ketamine at $p=6.26 \mathrm{E}-33(32,35)$. The top 10 disease gene risk variant categories enriched in the ketamine pharmacogenomic network include cognitive impairment, dissociative disorder, and mood disorders. These results point to a ketamine pharmacogenomic network in the human CNS, because the most significant biological functions of the network are consistent with what is known about ketamine's mechanisms, including NMDAR and glutamate neurotransmission (5-9). The ketamine pharmacogenomic network genes and regulatory RNAs exhibit circumscribed localization within 41 TADs, or less than $2 \%$ of human TADs (36).

\section{Component sub-networks of the ketamine pharmacogenomic network}

Gene set optimization resulted in 2 distinctly different sub-networks. The glutamate receptor subnetwork is enriched for synaptic signaling, glutamate receptor signaling, glutamate pathway regulation and chromatin organization. The top xenobiotic (chemical-drug) up-regulator of the 
glutamate receptor sub-network is ketamine at $p=2.1 \mathrm{E}-09$ (Figure 2A) $(32,35)$. In contrast, the neuroplasticity sub-network is enriched for regulation of nervous system development, regulation of neurogenesis, regulation of neuronal differentiation, neurogenesis and nervous system development (Figure 2B) (34). The neuroplasticity sub-network exhibits significant overlap with the "cardiovascular disease, neurological disease and organismal injury abnormalities" network category as determined by $\operatorname{IPA}^{\mathrm{TM}}(32)$ at $p=1 \mathrm{E}-59$ and its top xenobiotic up-regulator is also ketamine at $p=6 \mathrm{E}-12$ (Figure 4) $(32,35)$.

A

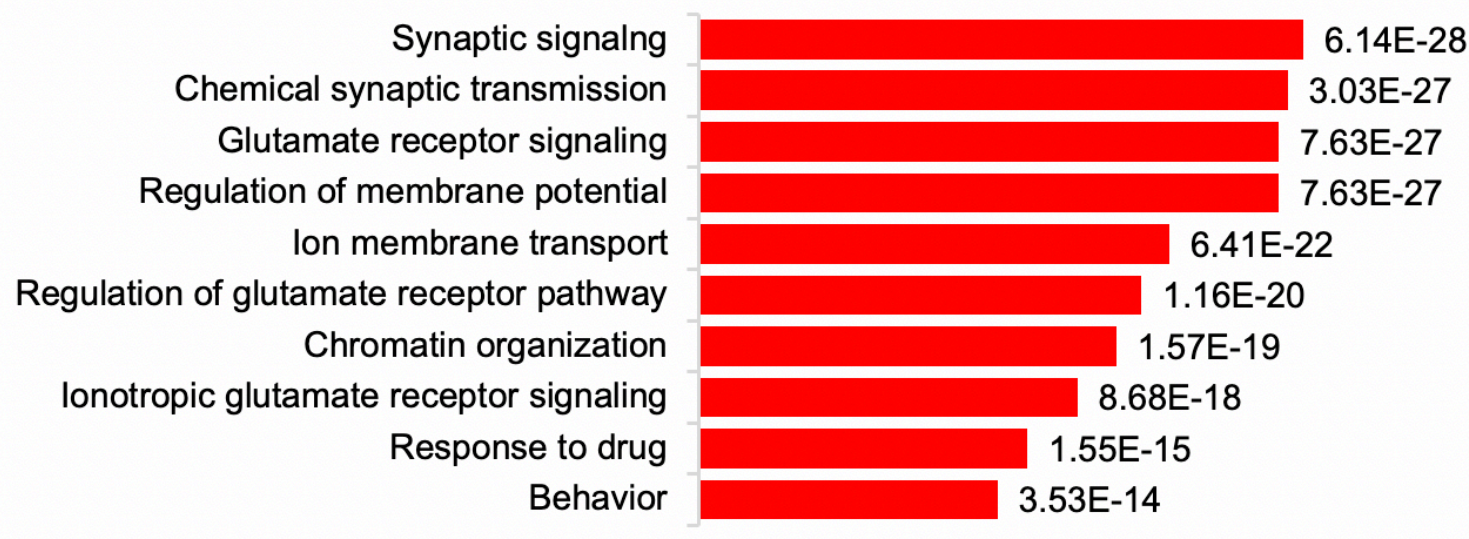

B

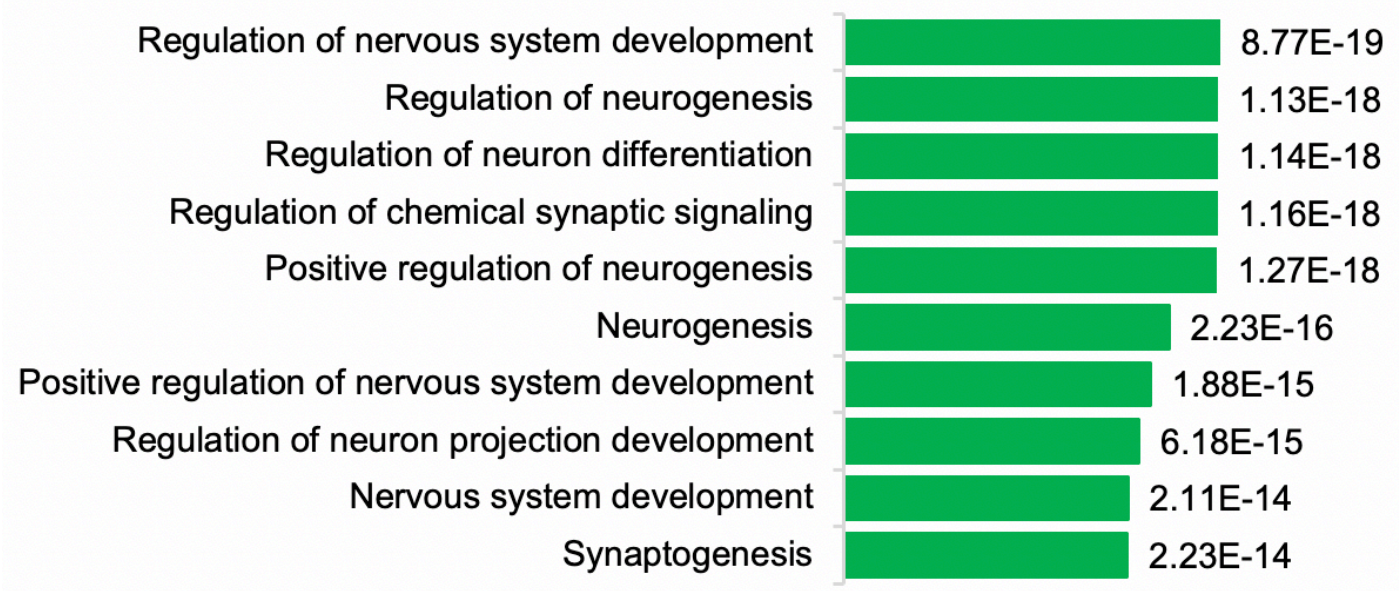

Figure 2. The 10 most significant biological processes from Gene Ontology for the two out of three ketamine pharmacogenomic sub-networks in human brain. (A) The ketamine glutamate receptor sub-network; (B) The ketamine neuroplasticity receptor sub-network. Statistical enrichment using GO (34) for "Homo sapiens" and "nervous system." 


\section{The ketamine glutamate receptor sub-network}

Our computational pipeline, based on ketamine-response genes selected from published results, showed differences in disease risk annotation between the glutamate receptor sub-network and the neuroplasticity sub-network, even though the products of both sub-networks are regulated by ketamine. Pathway analysis shows that the glutamate receptor sub-network is significantly associated with cognitive impairment, bipolar disorder, postoperative delirium, schizophrenia affective disorder, schizophrenia, non-cancer pain, postoperative pain, vomiting, nausea, and unconsciousness (Figure 3).

Analysis of glutamate receptor sub-network genes using Gene Ontology (31) for human CNS biological processes shows the genes CACNA1C, CACNB2, DLG4, GRIN1, GRIN2A, GRIN2B, GRIN2C, GRIN2D, GRIN3A are significantly enriched for NMDA glutamate neurotransmission. The genes SETDB1, TRIM28 and ZNF274 are enriched for chromatin remodeling in neuronal differentiation, and BRD1, EHMT1 and MBD1 are enriched for histone 3 lysine 9 (H3K9) methylation. Different bioinformatic applications (32-35) and GWAS disease risk and pharmacogenomic SNP annotations (37) showed that essential genes associated with cognitive impairment include ATFIP, BORCST, GRIA4 and GAD1. Mutations in the calcium channel gene $C A C N A 1 C$ has been significantly associated with schizophrenia spectrum disorders, including bipolar I disorder, as have CACNB2, GRIN2A and HCN1 (Supplementary Table 4). Postoperative delirium has been associated with the expression of $A C H E, C H R M 2, G A B R A 2$, GABRA5, GLRA1, GLRB, GRIA1, including genes that encode the protein constituents of the NMDA receptor. Nausea and vomiting, common side effects of ketamine therapy, have been associated with cholinergic and opiate gene expression. 


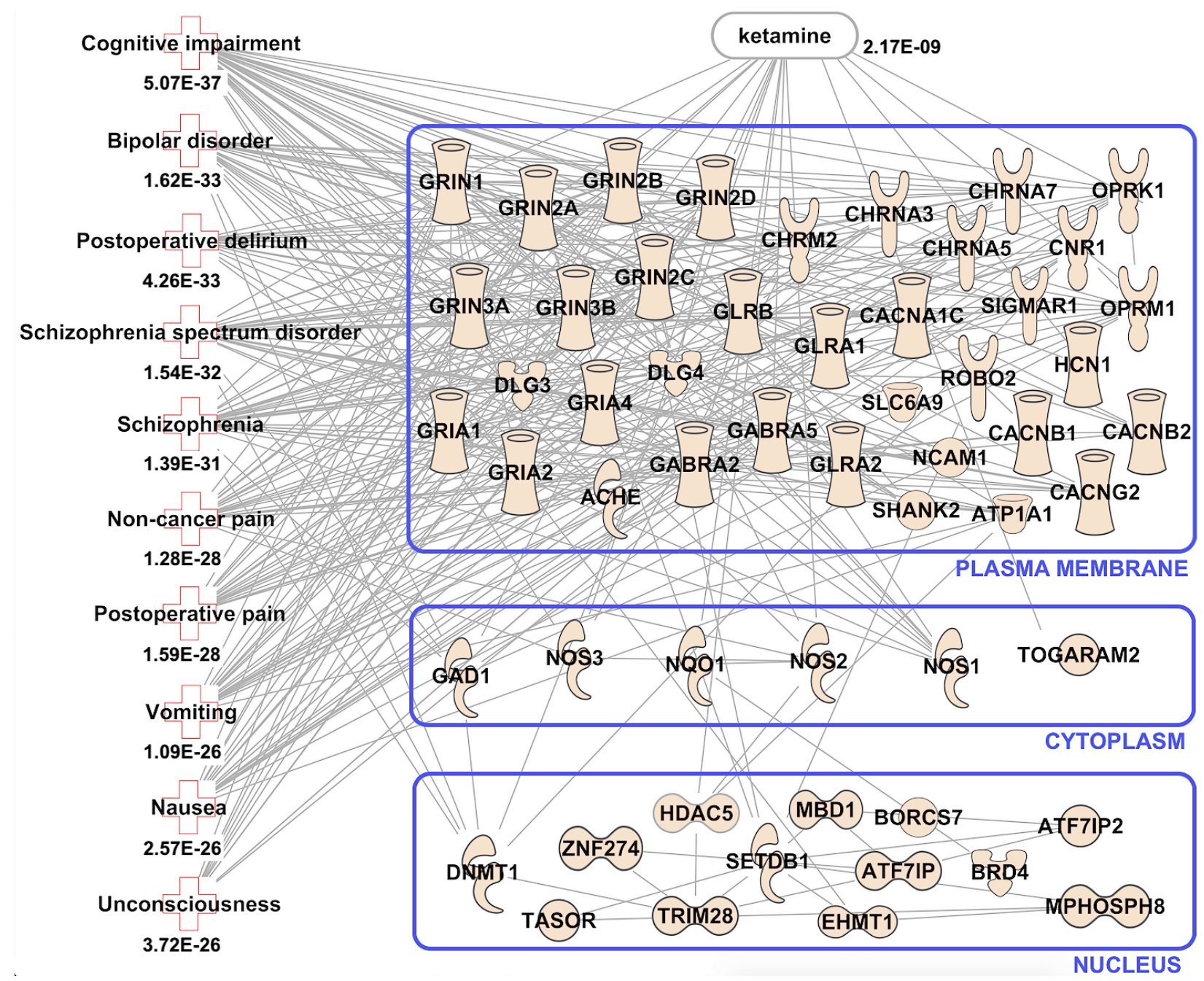

Figure 3. Diseases and conditions associated with the ketamine pharmacogenomic glutamate receptor sub-network, based on the published literature, and visualized using IPA ${ }^{\mathrm{TM}}$ (32). Lines between the symbols indicate significant interconnectivity as defined by IPA $^{\mathrm{TM}}$ (32), STRING (33) and KEGG (35), but do not provide information about the nature of the relationships between genes, their protein products, or regulatory RNAs. Supplementary Table 2A lists the gene definitions for the members of the ketamine glutamate receptor sub-network. Key to gene symbols:

\begin{tabular}{|c|c|c|c|c|}
\hline$\bullet$ & Chemical/Toxicant & \} & Enzyme & G-protein Coupled Receptor \\
\hline$\square$ & Ion Channel & $\widetilde{S}$ & Kinase & Other \\
\hline 9 & Peptidase & 0 & Phosphatase & Transcription Regulator \\
\hline 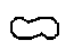 & Translation Regulator & U & Transmembrane Receptor & Transporter \\
\hline & Other & كُ & Disease & Relationship \\
\hline
\end{tabular}




\section{The ketamine neuroplasticity sub-network}

The neuroplasticity sub-network is significantly associated with emotional behavior, abnormal morphology of the nervous system, abnormal morphology of brain, depression, anxiety, and abnormal morphology of neurons (Figure 4). Enrichment of sub-network members using Gene Ontology (31) for human CNS biological processes associates the genes $A R C, C A M K 2 A, C N R 1$, ROBO2, SEMA3A, SLT1 and SLIT with synaptic and dendritic plasticity, and $A S C L 1, C U X 2$, BDNF, DCC, KLF6, NEUROD1, NEUROD2, NHLH2, SYN1, SYN2, TBR1 and TCF4 with neurogenesis.

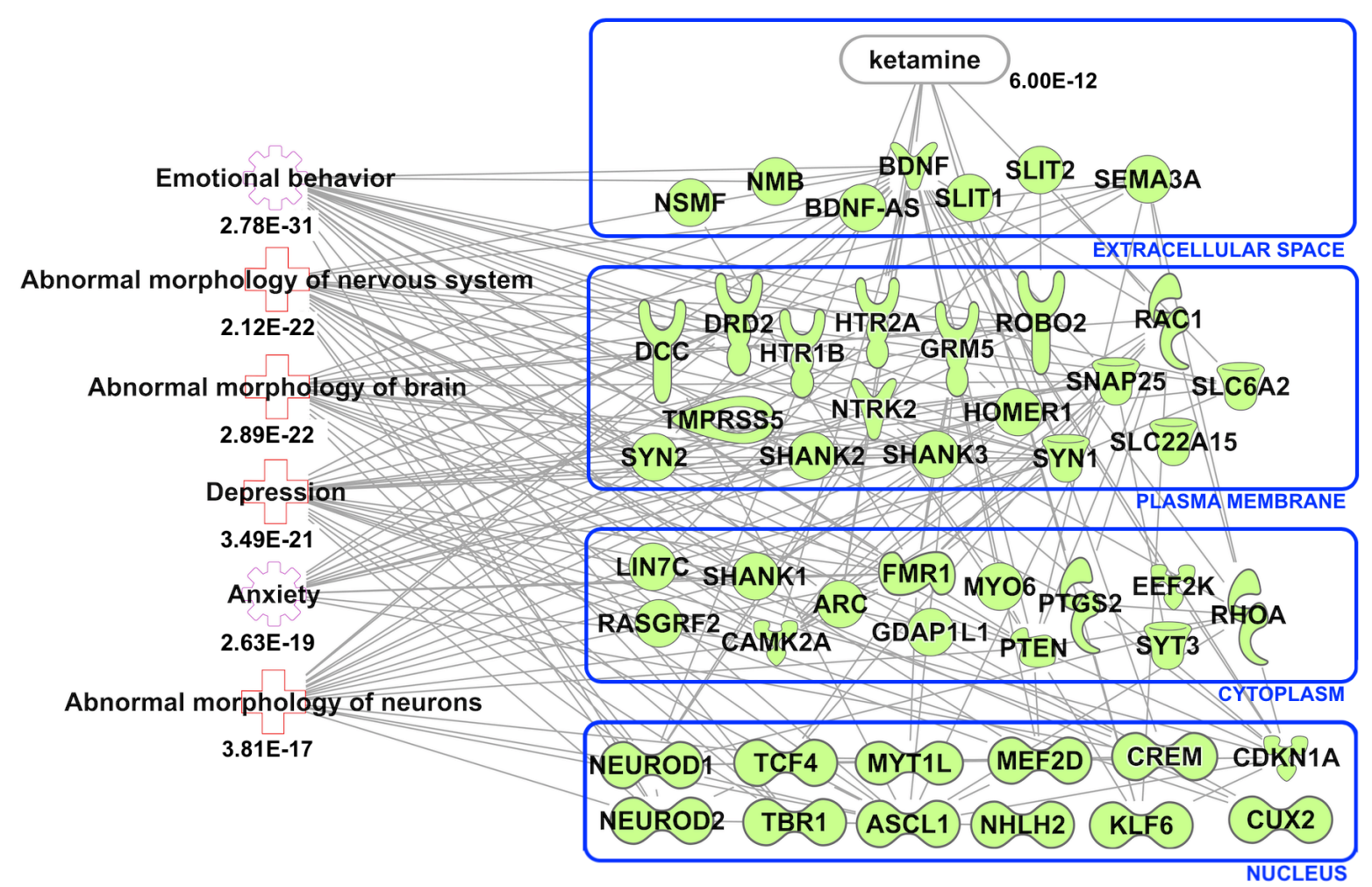

Figure 4. Diseases and conditions associated with the ketamine neuroplasticity sub-network, based on the published literature, and visualized using $\operatorname{IPA}^{\mathrm{TM}}(32)$. Lines between the symbols indicate significant interconnectivity as defined by IPA ${ }^{\mathrm{TM}}$ (32), STRING (33) and KEGG (35), but do not provide information about the nature of the relationships between genes, their protein products, or regulatory RNAs. Supplementary Table 2B lists the gene definitions for the members of the ketamine glutamate receptor sub-network. The Key for the symbols in this figure is shown in the caption of Figure 3. 


\section{The ketamine pharmacokinetic sub-network}

A third pharmacokinetic sub-network contains genes that encode cytochrome P450 enzymes, $C Y P 2 B 6, C Y P 2 A 6$ and $C Y P 3 A 4$, whose products are responsible for the metabolism of ketamine enantiomers $(8,12)$. This sub-network also contains the ESR1 gene, which encodes the estrogen receptor alpha subunit (37), and TCERG1, which encodes a nuclear protein that regulates transcriptional elongation and pre-mRNA splicing (38) (Figure 5). The ketamine pharmacokinetic sub-network also contains genes from the other sub-networks, including ANAPC2, DLG4, EFF2K, GRIA1, GRIA4, GRIN1, GRIN2B, MYO6 and ROBO2, so is not significantly different from the other two ketamine sub-networks.

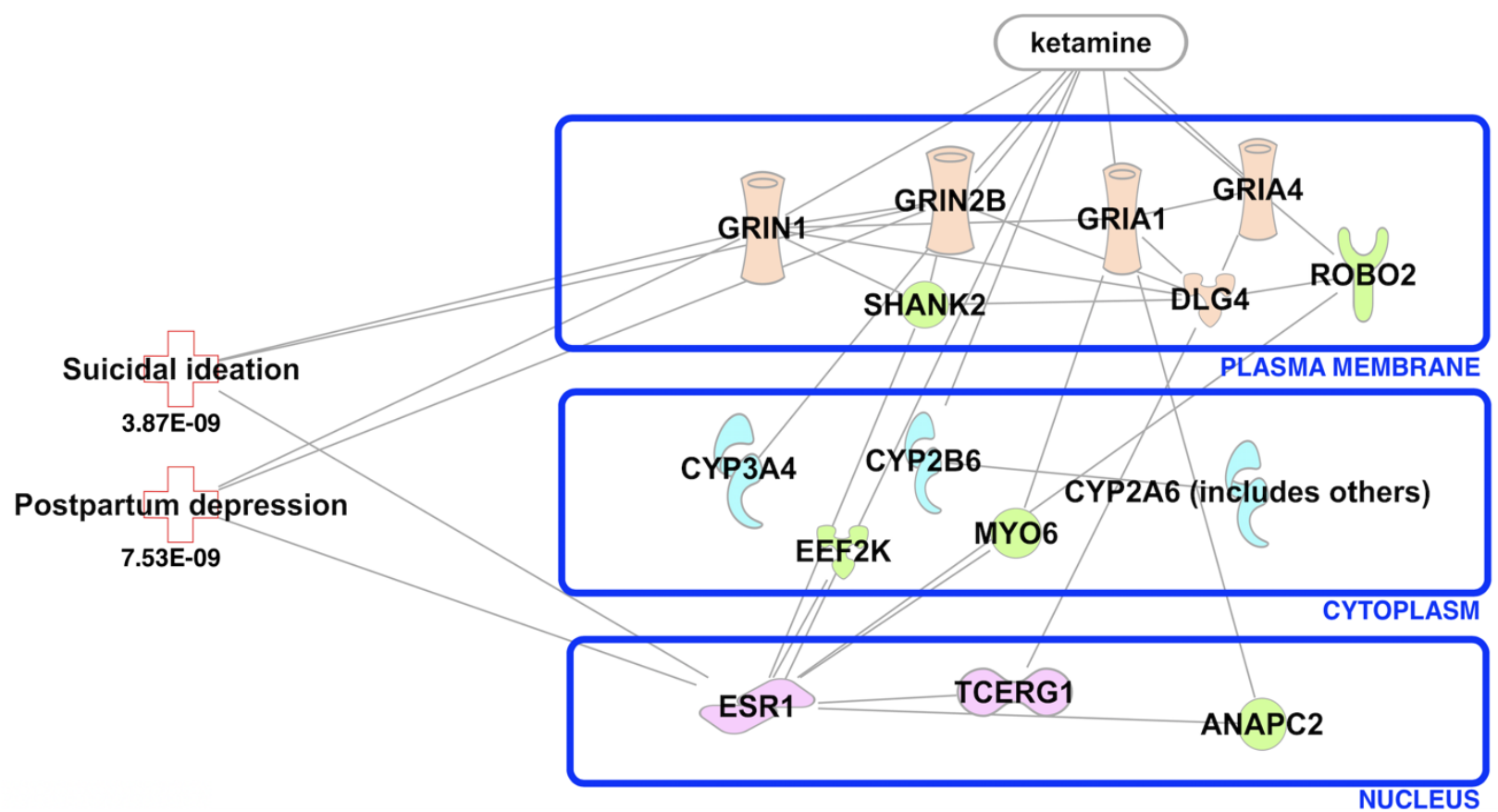

Figure 5. Diseases and conditions associated with the ketamine neuroplasticity sub-network, based on the published literature, and visualized using $\operatorname{IPA}^{\mathrm{TM}}(32)$. Lines between the symbols indicate significant interconnectivity as defined by $\operatorname{IPA}^{\mathrm{TM}}$ (32), STRING (33) and KEGG (35), but do not provide information about the nature of the relationships between genes, their protein products, or regulatory RNAs. Supplementary Table 2C lists the gene definitions for the members of the ketamine glutamate receptor sub-network. The Key for the symbols in this figure is shown in the caption of Figure 3. Supplementary Table 2C lists the gene definitions for the members of the ketamine glutamate receptor sub-network. The Key for the symbols is shown in the caption of Figure 3. 


\section{GWAS disease risk SNPs and Hi-C loops discriminate 2 ketamine sub-networks}

We hypothesized that psychiatric and social genotype-phenotype associations from GWAS may be useful in the functional characterization of the effects of ketamine in humans, in addition to published GWAS SNPs associated with dissociation and antidepressant measures in response to ketamine $(15,37)$. Because the majority of GWAS SNPs are located within intergenic and intragenic enhancers $(28,30,38)$ we tested whether GWAS disease risk located within the ketamine glutamate receptor and ketamine neuroplasticity sub-networks were likely to be located within chromatin loops in neural cells (SK-N-SH, H1, A735 cell lines and postmortem brain). If the GWAS SNPs contained in the sub-networks were predicted to be causal in the appropriate human surrogate tissue types, either neural (SK-N-SH, H1) or astrocyte (A735) cells but not in a liver cell line (HepG2) or in a white blood cell using multiple machine learning algorithms (3945), they were used to probe public Hi-C datasets using a bioanalytic method developed in our laboratory (46) (Materials and Methods).

We found a total of 186 disease and pharmacogenomic association signals for SNPs predicted to be causal within the ketamine glutamate receptor sub-network and within the ketamine neuroplasticity sub-network. These 186 signals correspond to 108 non-overlapping SNPs and 78 SNPs were significantly associated with at least two traits. The 78 multi-trait SNPs were located either in the ketamine glutamate receptor sub-network or the ketamine neuroplasticity subnetwork, but not in both sub-networks. Machine learning predicted that all of the sub-network SNPs were causal. The threshold for predicted causality required consensus of the numerical scores output from five different machine learning algorithms (39-44) and a deep learning software application (45) (Materials and Methods). When compared to the scores generated from a 
random selection of ten GWAS SNPs for all human traits with $p$-values at 5E-08 or lower, every score for each of the GWAS SNPs contained within these two sub-networks was designated as casual (Supplementary Table 4, Supplementary Table 5). Phenotype associations were carefully evaluated from source publications to eliminate those that were entirely self-reported or were ambiguous in terms of assignment to a coded psychiatric disorder $(37,47)$. The 186 GWAS signals associated with genes and regulatory RNAs that were members of the ketamine pharmacogenomic sub-networks identified in this study were annotated by disease risk, psychiatric subtype, enhancer, eQTL, Hi-C score (from both public data and our own adjustable bin mapping method) and co-localization with enhancer RNA. These 186 signals comprised 108 unique GWAS disease risk and pharmacogenomic SNPs predicted to be casual, including 78 SNPs with signals for multiple traits, exhibited clear genotype-phenotype association differences that discriminated the ketamine glutamate receptor sub-network from the ketamine neuroplasticity sub-network (Table 1), although there was overlap for certain genetic associations including schizophrenia and smoking and recurrent depression (Supplementary Table 4, Supplementary 5).

Table 1A shows that multiple GWAS disease risk SNPs located within the glutamate receptor subnetwork can be annotated as enhancers associated with tobacco smoking status, chronic schizophrenia (ICD diagnostic code F20), and bipolar 1 disorder (ICD diagnostic codes F31.0 F31.64). Table 1B shows that the ketamine neuroplasticity sub-network contains multiple GWAS disease risk SNPs that can be annotated as enhancers associated with recurrent depression (ICD code F33), alcoholism and response to ketamine. The results shown in Table 1, Supplementary Table 4, and Supplementary Table 5 demonstrate that enhancer SNPs co-localize with a limited number of genes within each sub-network. 
A. The ketamine glutamate receptor sub-network

\begin{tabular}{|l|l|l|l|l|l|l|l|}
\hline GWAS SNP & Populations & Gene(s) & Reported trait & $\begin{array}{l}\text { Reported } \\
\text { P-value }\end{array}$ & $\begin{array}{l}\text { Enhancer, } \\
\text { cell type }\end{array}$ & $\begin{array}{l}\text { Hi-C score: } \\
\text { Human brain }\end{array}$ & PMID \\
\hline rs1051730 & ASN, EUR & $\begin{array}{l}\text { CHRNA5, } \\
\text { CHRNA3 }\end{array}$ & Smoking status & $6 \mathrm{E}-121$ & Neuron & $\begin{array}{l}\text { 1E-27: Nucleus } \\
\text { accumbens }\end{array}$ & 30617275 \\
\hline rs28681284 & ASN & $\begin{array}{l}\text { CHRNA5, } \\
\text { CHRNA3 }\end{array}$ & $\begin{array}{l}\text { Schizophrenia, } \\
\text { chronic (F20) }\end{array}$ & $6 \mathrm{E}-13$ & Neuron & $\begin{array}{l}1 \mathrm{E}-27 \text { : Nucleus } \\
\text { accumbens }\end{array}$ & 30285260 \\
\hline rs2007044 & ASN & CACNA1C & $\begin{array}{l}\text { Schizophrenia, } \\
\text { chronic (F20) }\end{array}$ & $6 \mathrm{E}-20$ & $\begin{array}{l}\text { Bipolar } \\
\text { neuron }\end{array}$ & $\begin{array}{l}\text { 1E-10: Cingulate } \\
\text { cortex }\end{array}$ & 29483656 \\
\hline rs7192140 & EUR & GRIN2A & Smoking status & $2 \mathrm{E}-15$ & $\begin{array}{l}\text { Bipolar } \\
\text { neuron }\end{array}$ & $\begin{array}{l}\text { 1E-19: Frontal } \\
\text { cortex }\end{array}$ & 30643251 \\
\hline rs11647445 & EUR & GRIN2A & $\begin{array}{l}\text { Bipolar I disorder } \\
\text { (F31.0 - F31.64) }\end{array}$ & $1 \mathrm{E}-10$ & $\begin{array}{l}\text { Bipolar } \\
\text { neuron }\end{array}$ & $\begin{array}{l}\text { 1E-19: Frontal } \\
\text { cortex }\end{array}$ & 31043756 \\
\hline rs7893279 & ASN, EUR & CACNB2 & $\begin{array}{l}\text { Schizophrenia, } \\
\text { chronic (F20) }\end{array}$ & $9 \mathrm{E}-14$ & Neuron & $\begin{array}{l}\text { 1E-10: Frontal } \\
\text { cortex }\end{array}$ & 30285260 \\
\hline rs111294930 & EUR & $\begin{array}{l}\text { LINC01470, } \\
\text { GRIA1 }\end{array}$ & $\begin{array}{l}\text { Schizophrenia, } \\
\text { chronic (F20) }\end{array}$ & $9 \mathrm{E}-12$ & $\begin{array}{l}\text { Bipolar } \\
\text { neuron }\end{array}$ & $\begin{array}{l}\text { 1E-12: Cingulate } \\
\text { cortex }\end{array}$ & 29483656 \\
\hline rs9292918 & ASN & HCN1 & $\begin{array}{l}\text { Schizophrenia, } \\
\text { chronic (F20) }\end{array}$ & $4 \mathrm{E}-11$ & $\begin{array}{l}\text { Bipolar } \\
\text { neuron }\end{array}$ & $\begin{array}{l}\text { 1E-10: Frontal } \\
\text { cortex }\end{array}$ & 28991256 \\
\hline rs62367520 & EUR & HCN1 & Smoking status & $1 \mathrm{E}-10$ & $\begin{array}{l}\text { Bipolar } \\
\text { neuron }\end{array}$ & $\begin{array}{l}\text { 1E-10: Frontal } \\
\text { cortex }\end{array}$ & 29283656 \\
\hline
\end{tabular}

B. The ketamine neuroplasticity sub-network

\begin{tabular}{|l|l|l|l|l|l|l|l|}
\hline GWAS SNP & Populations & Gene(s) & Reported trait & $\begin{array}{l}\text { Reported } \\
\text { P-value }\end{array}$ & $\begin{array}{l}\text { Enhancer, } \\
\text { cell type }\end{array}$ & $\begin{array}{l}\text { Hi-C score: } \\
\text { Human brain }\end{array}$ & PMID \\
\hline rs61902811 & EUR & $\begin{array}{l}\text { TMPRSS5, } \\
\text { DRD2 }\end{array}$ & $\begin{array}{l}\text { Recurrent } \\
\text { depression (F33) }\end{array}$ & $4 \mathrm{E}-39$ & Neuron & $\begin{array}{l}\text { 1E-04: } \\
\text { Hippocampus }\end{array}$ & 30718901 \\
\hline rs4936277 & EUR & $\begin{array}{l}\text { TMPRSS5, } \\
\text { DRD2 }\end{array}$ & $\begin{array}{l}\text { Alcohol use } \\
\text { disorder, alcohol } \\
\text { dependence }\end{array}$ & $1 \mathrm{E}-13$ & $\begin{array}{l}\text { Bipolar } \\
\text { neuron }\end{array}$ & $\begin{array}{l}1 \text { l.00E-06: } \\
\text { Nucleus } \\
\text { Accumbens }\end{array}$ & 29942085 \\
\hline rs7227069 & EUR & DCC & $\begin{array}{l}\text { Recurrent } \\
\text { depression (F33) }\end{array}$ & $2 \mathrm{E}-28$ & Neuron & $\begin{array}{l}\text { 1E-10: Cingulate } \\
\text { cortex }\end{array}$ & 30718901 \\
\hline rs12967143 & EUR & TCF4 & $\begin{array}{l}\text { Recurrent } \\
\text { depression (F33) }\end{array}$ & $2 \mathrm{E}-27$ & Neuron & $\begin{array}{l}1 \mathrm{E}-10 \text { : Frontal } \\
\text { cortex }\end{array}$ & 30718901 \\
\hline rs7932640 & EUR & GRM5 & $\begin{array}{l}\text { Recurrent } \\
\text { depression (F33) }\end{array}$ & $3 \mathrm{E}-25$ & Neuron & $\begin{array}{l}1 \mathrm{E}-04: \text { Cingulate } \\
\text { cortex }\end{array}$ & 30718901 \\
\hline rs139438618 & AFR & SEMA3A & $\begin{array}{l}\text { Major depression } \\
\text { and alcoholism }\end{array}$ & $2 \mathrm{E}-11$ & $\begin{array}{l}\text { Bipolar } \\
\text { neuron }\end{array}$ & $\begin{array}{l}1 \mathrm{E}-10: \text { Nucleus } \\
\text { Accumbens }\end{array}$ & 29071344 \\
\hline rs775766 & EUR & ROBO2 & $\begin{array}{l}\text { Recurrent } \\
\text { depression (F33) }\end{array}$ & $2 \mathrm{E}-08$ & Neuron & $\begin{array}{l}\text { 1E-14: Cingulate } \\
\text { cortex }\end{array}$ & 29942085 \\
\hline rs1400237 & EUR & ROBO2 & $\begin{array}{l}\text { Response to } \\
\text { ketamine in } \\
\text { depression }\end{array}$ & $8 \mathrm{E}-06^{*}$ & Neuron & $\begin{array}{l}\text { 1E-14: Cingulate } \\
\text { cortex }\end{array}$ & 30552316 \\
\hline
\end{tabular}

Table 1. Selected GWAS SNPs determined to be causal and annotated as enhancers located within (A) the ketamine glutamate receptor sub-network, and (B) the ketamine neuroplasticity subnetwork. Data sources used for GWAS and SNP annotation: columns 1-5, the NHGRI-EBI GWAS catalogue (37), column 6 , enhancer status determined using annotation from $(38,48-60)$, and column 7 using Hi-C data from $(46,61,62)$. eQTL data support the results shown in column $7(63,64)$. PMID in column 8 indicates PubMed identification number $(65)$. All the GWAS SNPs analyzed can be found in Supplementary Table 4 and Supplementary Table 5. *Significance increased by network boosting (66). 
The ketamine glutamate receptor sub-network contains SNPs that occur with greatest frequency in association with CHRNA3, CHRNA5, NCAM1, NOS3, CACN1AC, CACNB2, HCN1, an intergenic region between GRIA1 and LINC01470 and GRIN2A. The ketamine neuroplasticity sub-network contains SNPs that occur with greatest frequency in association with $T C F 4, D C C$, an intergenic region between DRD2 and TRMPSS5, and GRM5. These results demonstrate that mutational alteration of enhancer interactomes discriminate between the ketamine glutamate receptor sub-network (chronic schizophrenia, smoking status) and the ketamine neuroplasticity sub-network (recurrent unipolar depression, alcohol consumption).

\section{Ketamine enhancers are preferentially located in the cingulate cortex and the frontal cortex}

The distribution of GWAS SNPs, enhancer, super-enhancer, and chromatin spatial contacts are concentrated within the cingulate cortex and the frontal cortex for both the glutamate receptor subnetwork and the neuroplasticity sub-network. Figure 6 shows the neuroanatomical distribution of the 108 GWAS SNPs located within Hi-C loops in either the ketamine glutamate receptor or ketamine neuroplasticity sub-networks based on the published literature $(46,61,62)$. These results, combined with correlative mapping of gene expression within these sub-networks based on data from the human brain atlas of the Allen Brain Science Institute (67) and functional neuroimaging results from 24 studies of ketamine's rapid antidepressant response (Supplementary Table 1), support research demonstrating that cingulate cortex and frontal cortex are primary sites where the drug exerts its pharmacodynamic effects $(68,69)$. 

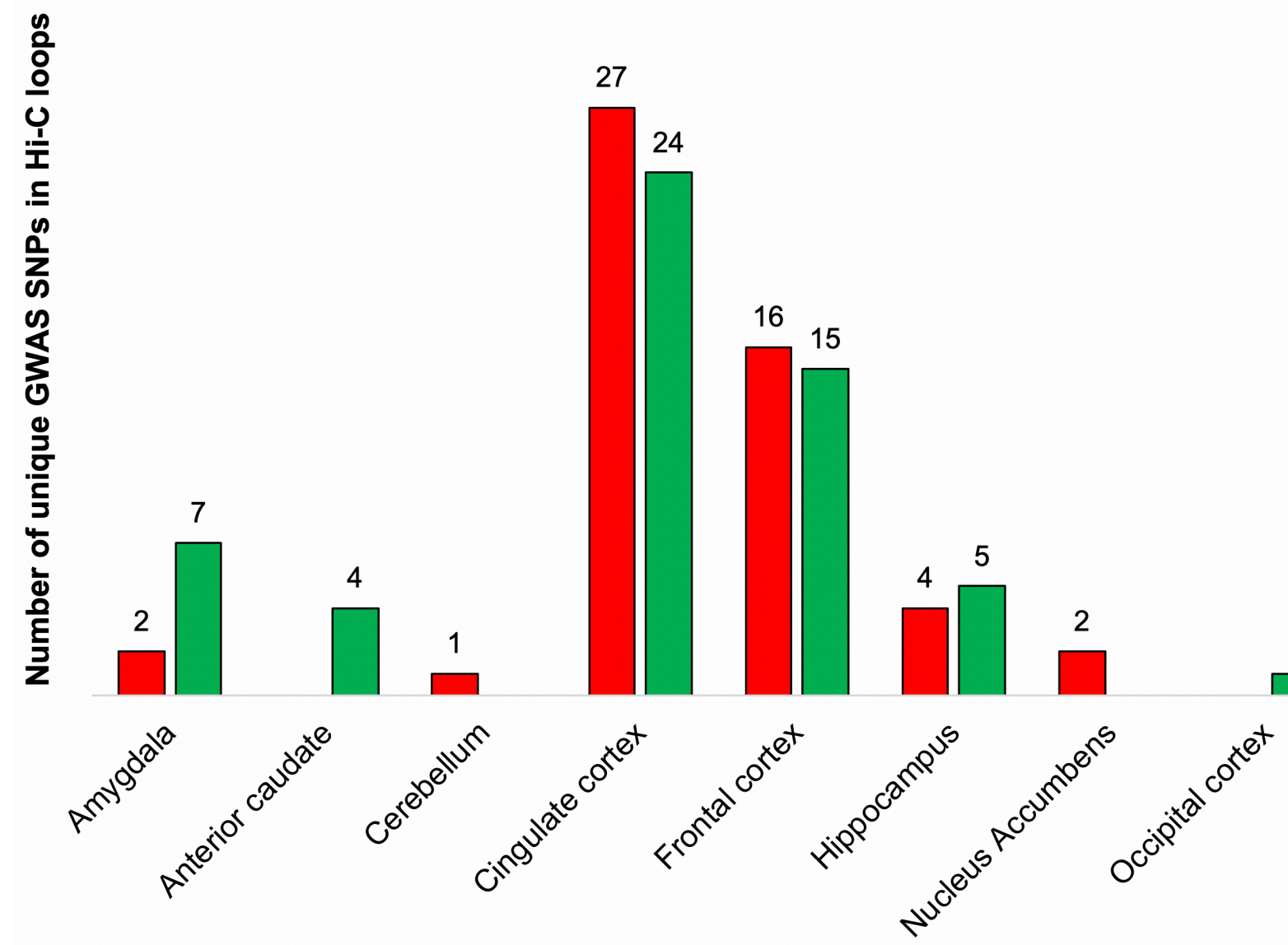

\section{Neuroanatomical Location}

Fig. 6. The neuroanatomical distribution of 108 non-overlapping GWAS disease risk and pharmacogenomic response SNPs located within Hi-C chromatin loops in the ketamine glutamate receptor sub-network (red) and the ketamine neuroplasticity sub-network (green). Details provided in Supplementary Tables 4 and 5.

Evidence in support of the ketamine pharmacogenomic network identified here is demonstrable by comparing the neuroanatomical distribution of gene expression data within the ketamine subnetworks with the localization results from a consensus brain-map showing which brain regions are first impacted by ketamine obtained from 24 neuroimaging studies (Supplementary Table 1). The consensus map emphasizes the anterior cingulate cortex (ACC), dorsolateral and dorsomedial prefrontal cortex (PFC), and the supplementary motor area (SMA) as consistently the first human 
brain regions to be activated by the drug, indicated by the dark red spheres in Supplementary

Figure 1A. However, other CNS regions have been reported in neuroimaging studies to be rapidly impacted by ketamine in humans following administration of the drug. These are shown in black in Supplementary Figure 1A but did not comprise the clear majority of brain regions reported to be first impacted by ketamine in the neuroimaging studies that we examined during our research. To serve as controls, we chose adjacent human brain regions not impacted by ketamine in the neuroimaging studies, including the corpus callosum (CC), occipital cortex (OC) and somatosensory cortex (SS). We were limited by available sources of gene expression data from postmortem human brain but did obtain reliable and non-conflicting data on 100 of the 107 genes in the ketamine network $(64,67)$. Also, the RNA sequencing (RNA-seq) results were not as well localized as the neuroimaging data, so this analysis was limited to obtaining RNA-seq data labeled as originating from anterior cingulate cortex (ACC), prefrontal cortex (PFC), corpus callosum (CC), somatosensory cortex (SS), and occipital cortex (OC). As shown in Supplementary Figure 1B, genes in the ketamine network are expressed at significantly higher levels in the ACC and PFC than in the neighboring $\mathrm{CC}, \mathrm{SS}$ and $\mathrm{OC}$, where there is no evidence that ketamine exerts rapid antidepressant effects. The ACC is part of the cingulate cortex, and the PFC is part of the frontal cortex, regions that are shown in Table 1, Supplementary Figure 2, Supplementary Table 4 and

\section{Supplementary Table 5.}

Publicly available in situ hybridization data of GRIN2B, GRIN1 and GLRB mRNA in postmortem human brain (Supplementary Figure 2) (67) shows that expression of these three key genes located in the ketamine glutamate receptor network is widespread in the telencephalon, including amygdala, anterior caudate, anterior cingulate cortex, frontal cortex, globus pallidus, 
hippocampus, prefrontal cortex, nucleus accumbens and putamen. However, there are differences in their neuroanatomical distribution. For example, GLRB shows circumscribed expression in layer VI of cortex, whereas GRIN2B and GRIN1 are expressed in the dentate gyrus of the hippocampal formation.

Whole genome, Hi-C data mapping performed using SNPs as data probes, the probes including SNPs contained within the ketamine sub-networks and obtained from the GWAS catalog (37), including those which has been significantly associated with disease risk and ketamine antidepressant response variation and dissociation (15). These results validated pathway analysis and demonstrated both cis- and trans-interactions with other members of the ketamine pharmacogenomic pathway within human neurons (Figure 7, Figure 8) (Materials and Methods). These spatial contacts are significantly enriched for association with specific superenhancers from cingulate cortex and frontal cortex (data not shown). Figure 7A shows a whole genome plot that is the key for understanding the gene-gene interactions shown in Figure 7B-7G, with each individual trans-interaction labeled using a different color (see Key). Figure 7B shows Hi-C contacts between $R A S G R F 2$, a gene associated with synaptic plasticity and alcoholism (70), with the co-localized nicotinic receptor genes CHRNA3 and CHRNA5 that contain SNPs significantly associated with smoking status in GWAS (37). Figure 7B shows trans-interactions between the ROBO2 gene, which contains a number of SNPs associated with both unipolar depression and dissociative and antidepressant responses to ketamine in $\operatorname{GWAS}(15,37)$, and both the GRIN2B gene and the ATF7IP gene. The ATF7IP gene encodes a chromatin remodeling protein responsible for HUSH-mediated heterochromatin formation and gene silencing as part of the stabilization of the SETDB1 complex, required for methylation of histone 3 lysine 9 (H3K9me3) 
during neuronal differentiation (71). The TCF4 gene, encodes a transcription factor that regulates neuronal differentiation $(15,37)$, and harbors multiple GWAS SNPs significantly associated with recurrent depression (Supplementary Table 4).

Figure 7D demonstrates a spatial contact between TCF4 and the GRM5 gene, which encodes a member of the glutamate metabotropic receptor family and contains enhancers significantly associated with depression in GWAS (Supplementary Table 4) (37). Figure 7E shows a Hi-C map of interactions between $C A C N A 1 C$ and the GRIN2A and the ATF7IP2 genes. In Figure 7C, Hi-C spatial contacts obtained from human glutamatergic neurons shows trans-interactions between the $C A M K 2 A$ gene located on chromosome 5 with the genes GRIN1 and ANAPC2 located on chromosome 9. The ANAPC2 protein is part of a complex that controls the formation of synaptic vesicle clustering at the active zone to the presynaptic membrane in postmitotic neurons, and this complex also degrades NEUROD2 as a primary component of pre-synaptic differentiation during neuronal differentiation (72). Figure 7G shows spatial contacts in neurons between the DRD2 gene and the RHOA gene, which encodes a signaling protein that regulates the cytoskeleton during synaptic transmission in neurons (73). 
A

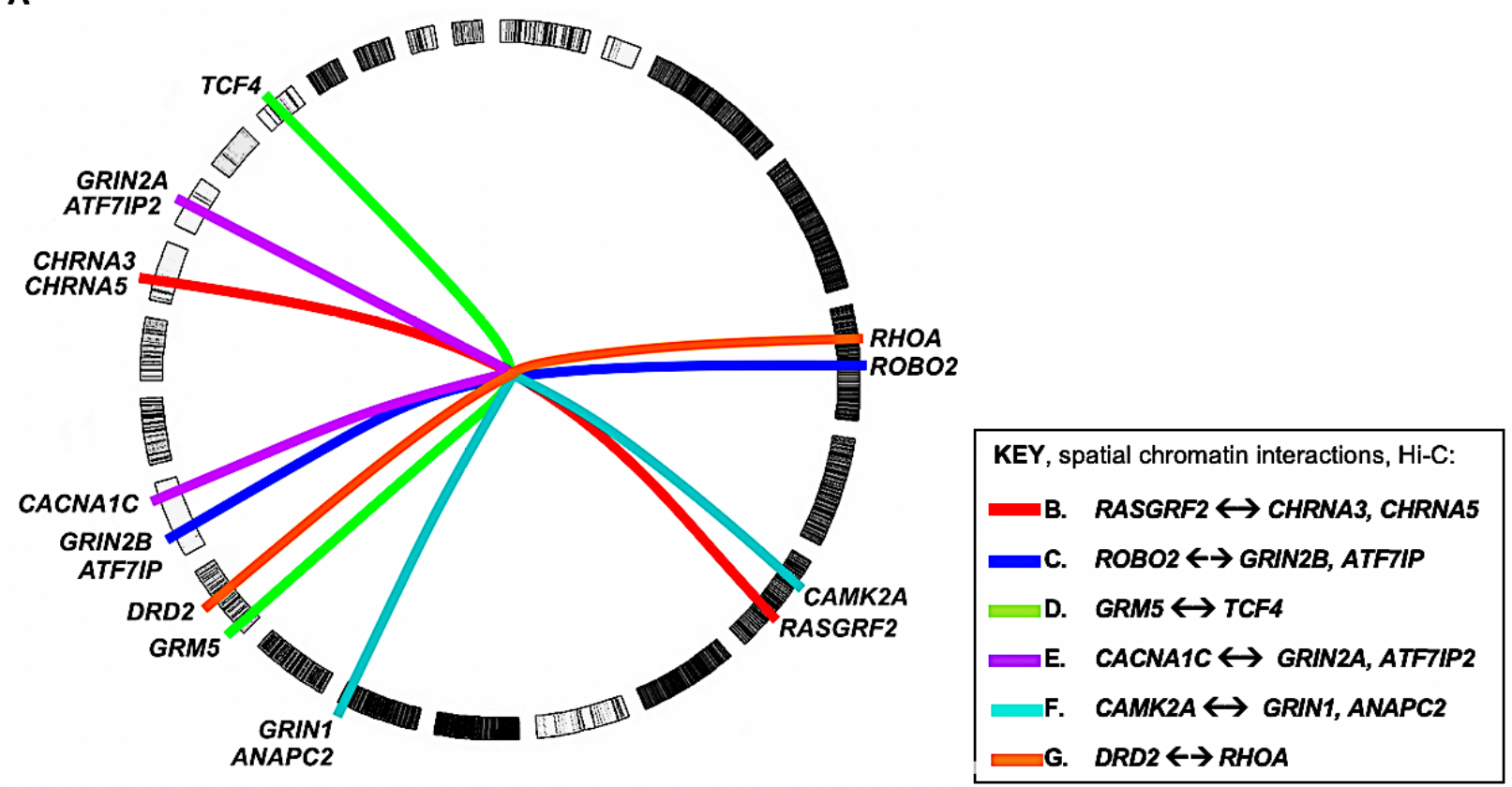

B

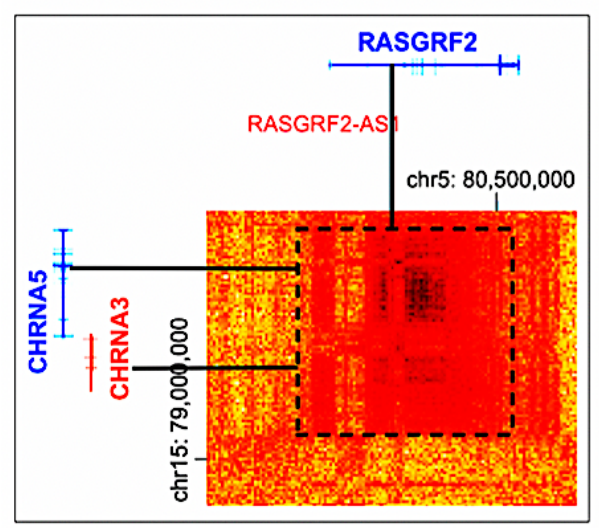

E

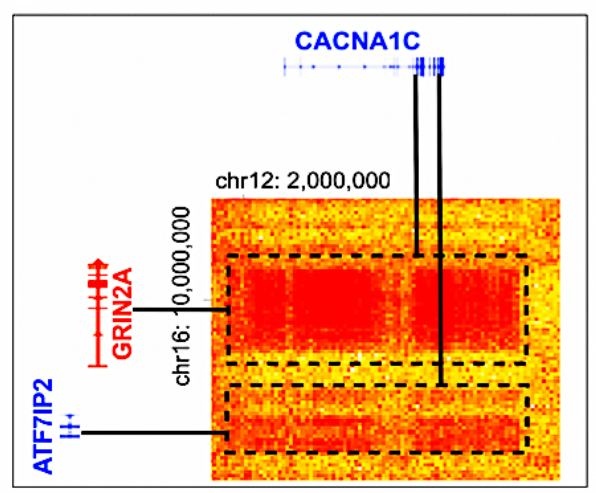

C

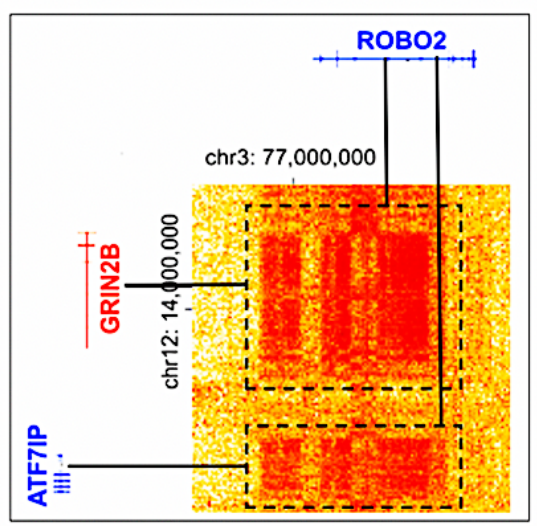

$\mathbf{F}$

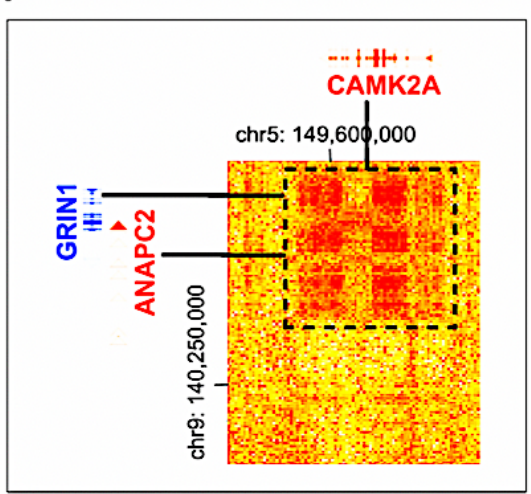

D

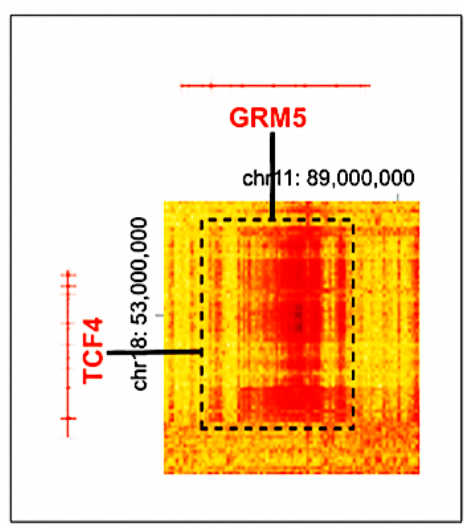

G

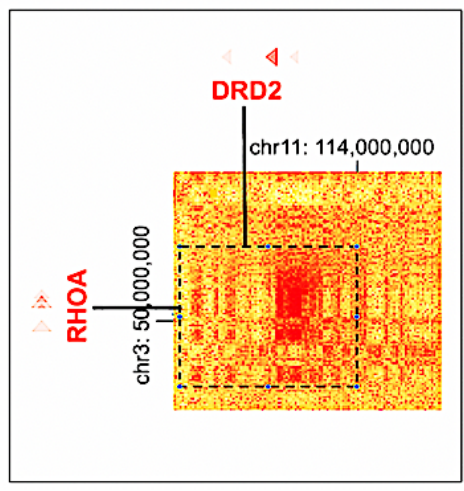

Fig. 7. Example of the trans-interactions of ketamine pharmacogenomic network SNPs. The intensity heat maps demonstrate individual spatial $\mathrm{Hi}-\mathrm{C}$ contacts between genes in human neurons, including (A) CACNAIC and GRIN2A (blue line); (C) RASGRF2 and CHRNA3 CHRNA5 (orange line); (D) CAMK2A and GRIN1, ANPAC2 (red line); (E) DRD2 and RHOA (light blue line); (F) 
GRM5 and TCF4 (purple line); (G) ROBO2 and GRIN2B, ATF7IP (green line); (B) Whole genome plot serves as key showing individual gene-gene interactions by color with the corresponding colored line located next to letters in Figure 7A, C-G. Images from Hi-C data visualization using the HiGlass software (74), and coordinates are based on human genome build hg19 of the UCSC browser (75).

Figure 8 compares the local cis-interactions and organization of the loci containing the GRIN2A and GRIN2B genes in human glutamatergic neurons. In both cases, related genes are organized as triplets on different chromosomes, with the GRIN2A, ATF7IP2 and EMP2 genes on chromosome 16, and the GRIN2B, ATFIP and EMP1 genes on chromosome 12. It is not known whether the colocalization of these 3 related genes is a coincidental, possibly a consequence of a conserved genomic duplication occurring during evolution and/or functional relatedness. Figure 8 shows putative chromatin loops (magnified circles).

A

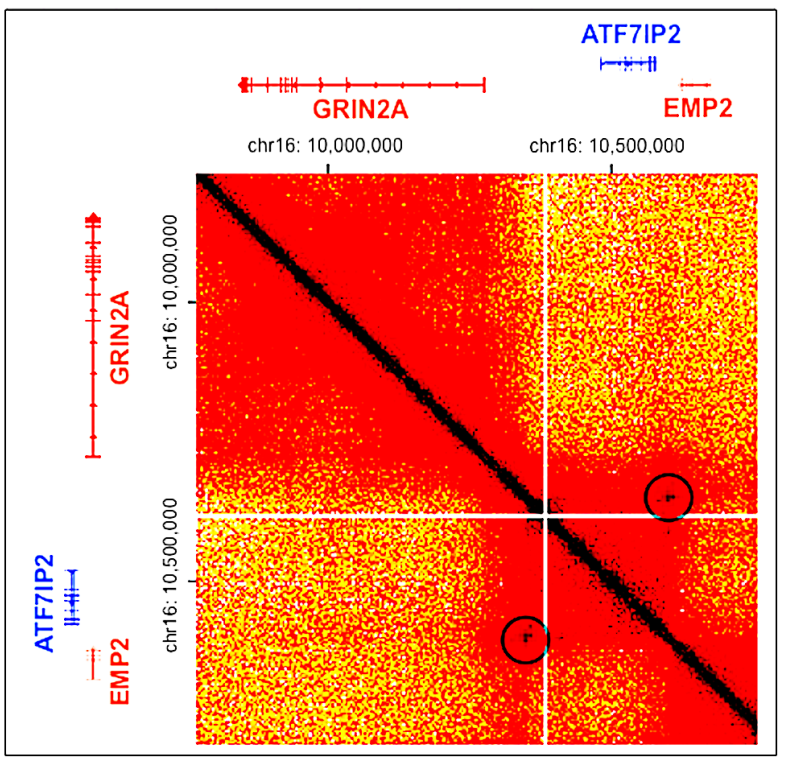

B

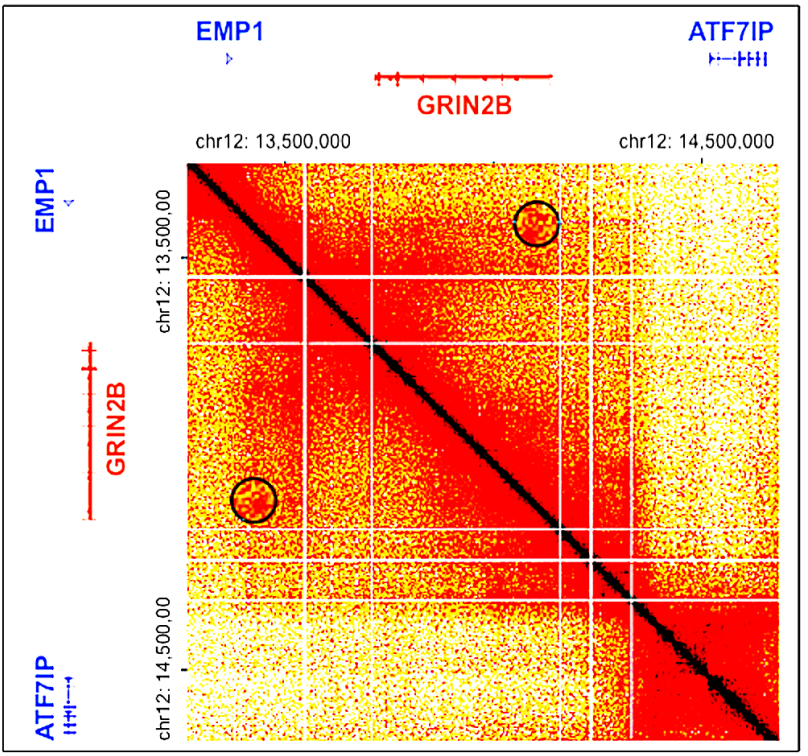

Fig. 8. Organization of the Hi-C loci containing the glutamate receptor genes $G R I N 2 A$ and GRIN2B in human glutamatergic neurons. (A) Hi-C matrix showing the co-localized genes GRIN2A, ATF7IP2 and EMP2 (B) Hi-C matrix showing the co-localized genes GRIN2B, ATF7IP and $E M P 1$. Circles indicate possible loop domains magnified by $2 \mathrm{X}$. Images from Hi-C data visualization using the HiGlass software (74), and coordinates are based on human genome build hg19 of the UCSC browser (75). 


\section{Discussion}

\section{The ketamine pharmacogenomic sub-networks}

We have identified a ketamine pharmacogenomic network in the human brain using multi-scale biological data analysis. Our approach used multiple, reinforcing data sources and algorithms, as well as results spanning different levels of resolution, ranging from disease risk genotypephenotype associations obtained from GWAS to functional neuroimaging of rapid antidepressant response in the human brain following ketamine administration. Special emphasis has been placed on discretization of the enhancer interactome and chromatin interactions in the context of pharmacogenomic efficacy and adverse events. Results from all of the methods applied at different scales of resolution produced consistent findings, demonstrating that this novel strategy provides a useful application for data-driven bioinformatics discovery of psychotropic drug mechanisms for future applications (Figure 1). The research reported here also provides an in-silico design framework for subsequent study of pharmacogenomic networks in other therapeutic categories.

This research emphasizes the role of the regulatory genome, including enhancer and superenhancer-based interactomes, as an approach that provides insight into pharmacogenomic network mechanisms (22-25). It differs from pathway modeling methods in which altered protein folding based on missense codon variants and fixed signaling pathways serve as the foundation for the interpretation of the molecular substrate of ketamine response in humans. For example, we found no evidence for the inclusion of SNPs within proposed key signaling pathways in the ketamine network such as $A K T 1, M T O R$, or $E R K 1$, or participation of the inflammasome in this network (NLRP3 pathway) $(10,17,76,77)$. Although we do not find inflammatory genes in this ketamine network, the drug has shown promise as an investigational therapy for some 
inflammatory disorders (8). We did find evidence supporting the inclusion of the pharmacokinetic genes $C Y P 2 B 6$ and $C Y P 3 A 4$, in addition to ESR1 and GRIA1, GRIA4 within the ketamine network in human brain consistent with recent studies $(12,78)$, although more study is needed to show how proteins encoded by these genes in the brain contribute to ketamine response in humans.

One possible limitation of this research is that it relies, in part, on public and commercial databases that may contain erroneous information including uncorrected confirmation bias in published literature, deprecated primary source material, and results obtained using flawed statistical methods and/or methods based on spurious assumptions. To mitigate error associated with reliance on a single data type, the approach in this study used multiple, related data sources and algorithms, spanning different levels of resolution ranging from disease risk genotype-phenotype associations obtained from GWAS to functional neuroimaging of rapid antidepressant response in the human brain following ketamine administration. Similar methods have been used to combine results from GWAS and neuroimaging data (79).

\section{The three-composite ketamine pharmacogenomic sub-networks}

This research suggests that a different pharmacogenomic sub-network may mediate antidepressant effects and the dissociative and psychotomimetic effects of ketamine. Thus, the function of one sub-network is characterized by neurogenesis and neuroplasticity, as previously shown as the mechanism of action for other antidepressant medications $(9,80,81)$. It is tempting to speculate that while ketamine may not directly cause neurogenesis in its role as an antidepressant in human brain, it may stimulate neurogenic transcription leading to renewal of intrinsic self-efficacy, a personality trait often lost in depression (82). In contrast, the subnetwork containing genes that encode glutamate receptor proteins such as GRIN, GRIN3A and 
GRIN2B not only contains the largest number of genes, but SNPs within enhancers of this subnetwork have been significantly associated with dissociative disorders such as schizophrenia and bipolar disorder, and postoperative delirium, vomiting, and nausea adverse events associated with ketamine administration. Finally, enhancer SNPs in the glutamate receptor sub-network versus the neuroplasticity sub-network stratify by ketamine efficacy with reduced dissociation versus increased dissociation in response to ketamine, respectively (15).

The ketamine pharmacogenomic network is preferentially localized in the anterior limb of the behavioral antidepressant connectivity network, including cingulate cortex and frontal cortex in the human brain. This connectivity network was confirmed using an array of different data types, including enhancer, superenhancer, eQTL and Hi-C scoring of chromatin loops for annotation of GWAS SNPs, expression mapping, functional neuroimaging studies, and examination of the cis- and trans-interactions of ketamine pharmacogenomic SNPs.

There is a need to better understand mechanisms through which ketamine and its analogues act in the human central nervous system and to uncouple the psychotomimetic adverse effects of this emerging class of promising therapeutics from mechanisms that mediate antidepressant action. Ketamine's action as an anesthetic, analgesic and sedative may be a consequence of the partial antagonism of NMDAR-mediated pain transmission, blocking central sensitization of ascending pain afferents from the dorsal horn. Thus, through dissociation, the patient no longer pays attention to ascending pain stimuli, detached from the conscious mind, in a dreamlike state often accompanied by memory impairment $(83,84)$. 


\section{Genotype-phenotype annotation of different ketamine sub-networks}

One challenge is to understand why certain phenotypes cluster within a specific ketamine pharmacogenomic sub-network. In the glutamate receptor sub-network of the larger ketamine pharmacogenomic network, significant genotype-phenotype associations that include smoking impacting the same genes as schizophrenia (Table 1A and Supplementary Table 4). In the ketamine neuroplasticity sub-network, significant enhancer annotations included unipolar depression, depressive symptoms and alcoholism. This lends credence to our hypothesis that mutational disruption of the enhancer interactome within a drug network may provide insight into pharmacogenomic response stratification.

There is substantial evidence that patients diagnosed with schizophrenia are more likely to be heavy smokers than are healthy controls (85-87) but cause and effect are not understood. Emerging research demonstrates that nicotine induces $C Y P 2 B 6$ gene expression by two to three orders of magnitude in the human brain but not in the human liver (14). Because the cytochrome P450 family 2 sub-member 6 enzyme encoded by the CYP2B6 gene is rate-limiting in the metabolism of ketamine and its enantiomers (88), patients suffering from one of the spectrum of dissociative disorders related to schizophrenia may use nicotine for self-medication (85); however this hypothesis remains speculative. While exon variants in the CYP2B6 gene may differentially alter splicing but not protein structure or function (89), mutations that alter CYP2B6 mRNA splicing in the human brain contribute significantly to ketamine response variation in humans $(90,91)$. Previous research and results from this study show that estrogen regulation of $C Y P 2 B 6$ gene expression can modulate differential response to ketamine in females 
(biological sex) (Figure 5) (92). These results indicate that dose optimization is critically dependent on a patient's endogenous drug profile, biological sex, and age $(12,91,92)$.

\section{Translation to clinical practice}

These results support the conclusion that variation in genomic regulatory networks can be translated into actionable drug selection and dose optimization in patients. This study demonstrates the potential of multi-scale biological data analysis for the in-silico prediction of drug response and serious adverse event profiles in patients based on normal variation in the non-coding enhancer interactome and the discretization of drug-disease networks based on common genotype-phenotype associations. Thus, the antidepressant and dissociative effects of ketamine and related glutamatergic modulators, including dextromethorphan, D-cycloserine, raspastinel and sarcosine, may be uncoupled based on the patient's genetic risk profile. In this manner, knowledge of the subordinate mechanistic sub-networks of ketamine and its enantiomers explain previously unrecognized mechanisms of action of this drug class, identifying additional targets for drug repurposing. This strategy also suggests possible clinically relevant indications for ketamine that extend beyond depression, surgical anesthesia, sedation, and acute analgesia. These include psychiatric and also stress-related disorders defined by similar mechanisms of neural injury and repair, including posttraumatic stress disorder, bipolar 1 disorder, fibromyalgia, peripheral neuropathy, inflammatory bowel disease, and global chronic pain. The clinical utility of this approach requires confirmation in preclinical and clinical studies. 


\section{Materials and Methods}

\section{Selection of ketamine-response genes}

The ketamine response workflow is based on the pharmacoepigenomics informatics pipeline (PIP) (22-25). Input genes to the data analysis pipeline first included those genes that encode proteins and constituents of macromolecular protein complexes obtained from past studies of the binding affinity of $(R, S)$-ketamine, $R$-ketamine and $S$-ketamine performed in microsomal and tissue preparations in rodents and humans. Genes were selected based on whether their protein products, either alone or as part of a larger complex, bound ketamine enantiomers at high affinity ranging from $0.1-100 \mu \mathrm{M}$. To identify proteins and protein complexes, we used a search string from January 1975- October 2019 that included a Boolean search string with the words, "ketamine"”, “( $R S)$-ketamine", “(R)-ketamine”, “(S)-ketamine”, "binding affinity”, "K"

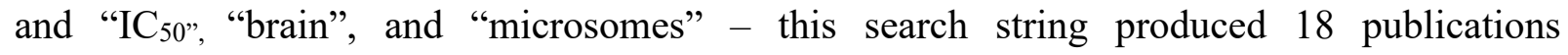
(Supplementary Table 1). This gene set included CACNA1C, CHRM2, CHRNA3, CHRNA5, CHRNA7, CNR1, DRD2, ESR1, GLRB, GRIA1, GRIA4, GRIN1, GRIN2A, GRIN2B, GRIN2C, GRIN2D, GRIN3A, GRIN3B, GRM5, HCN1, HTR1A, HTR1B, HTR2A, HTR3A, OPRK1, OPRM1, SIGMAR1, SLC6A2 and SLC6A3 (see also Supplementary Table 3.)

Further inputs identified candidate pharmacodynamic and pharmacokinetic genes obtained from published literature and drug databases, including DrugBank (93), Ingenuity Pathway Analysis ${ }^{\mathrm{TM}}$ (IPA ${ }^{\mathrm{TM}}$; Qiagen GmBH) (32), the Kyoto Encyclopedia of Genes and Genomes (KEGG) (35), and DrugCentral (94). This subset included genes not listed in the above set of candidate genes, but excluded pharmacodynamic targets that had not been shown to bind ketamine and its enantiomers at high affinity. This subset included genes and regulatory RNAs: $A C H E, A K T 1, A N A P C 2, A R$, 
ARC, ARNT, ASCL1, ATF7IP, ATF7IP2, ATP1A1, BDNF, BDNF-AS, BORCS7, CACNA1C,

CACNB1, CACNB2, CACNG2, CAMK2A, CDKN1A, CREM, CUX2, CYP2A6, CYP2B6, CYP2C9, CYPC19, CYP3A4, DCC, DLG3, DLG4, DNMT1, DOCK10, EDN2, EEF2, EEF2K, EHTM1, ENSG00000225960, ENSG00000251574, ERK1, ERK2, ESR1, FMR1, GABBR1, GABRA2, GABRA5, GAD1, GDAP1L1, GFAP, GLRA1, GLRA2, GRIP1, HDAC5, HK1, HMOX1, HOMER1, KLF6, LAMTOR1, LEP, LIN7C, MAPK1, MAPK8, MBD1, MEF2D, MPHOSPH8, MTOR, MTRNR2L2, MYO6, MYT1L, NMB, NCAM1, NEUROD1, NEUROD2, NLRP3, NMB, NOS1, NOS2, NOS3, NQO1, NR4A1, NSMF, NTRK2, PGBD1, PTGS2, PVALB, RAC1, RASGRF2, RHOA, ROBO2, RPTOR, SEC11A, SEMA3A, SETDB1, SHANK1, SHANK2, SHANK3, SLC6A9, SLC22A15, SLIT1, SLIT2, SNAP25, SYN1, SYN2, SYT3, TASOR, TBR1, TBX21, TCERG1, TCF4, TMPRSS5, TMPRRS6, TOGARAM2, TRIM26, TRIM28, ZNF274, ZNF592 and ZNF717.

Criteria for further selection of candidate genes was 2-fold. First, we determined whether the gene or regulatory RNA was expressed in human brain regions rapidly activated by ketamine enantiomers as determined by functional neuroimaging. The neuroanatomical distribution of the expression of genes in the ketamine network and its sub-networks were matched to a consensus map of brain regions rapidly activated by ketamine, based on the results of 24 neuroimaging studies in healthy controls and patients diagnosed with unipolar and bipolar depression (Supplementary Table 1). Second, we assessed whether this gene set formed a significantly interconnected pathway in human brain using neural cell- and tissue-specific filtering. Results were generated using IPA ${ }^{\mathrm{TM}}$ (Qiagen $\mathrm{GmBH}$ ) and verified using the STRING protein-protein interaction network database (33). Independent software applications for the post-hoc bioinformatics analysis included enrichment 
analysis using Gene Ontology's Panther web-based portal (34) and the gene expression module of $\mathrm{IPA}^{\mathrm{TM}}$ to determine disease risk based on published literature (32).

\section{Gene set optimization, pathway analysis and significant upstream molecular regulators}

Following reconstruction of the larger ketamine spatial network, it was deconstructed into its associative mechanistic sub-networks using an executable gene set optimization engine that iteratively compares gene function with efficacy, adverse events and other known features associated with ketamine response (Figure 9). The iterative mechanistic sub-network profiler comprises executable code that iteratively re-organizes interconnected gene sets within the drug spatial network until the most significant associations with the various mechanisms of action of the psychotropic drug are reached, based on multiple databases including Gene Ontology (34).

Independent pathway analysis software applications were used for the post-hoc bioinformatics analysis including the gene expression module of IPA ${ }^{\mathrm{TM}}$ (32) and KEGG (35) to determine disease risk, based on results extracted from the published literature. In addition, ketamine sub-network genes were annotated using data from the EBI-NHGRI GWAS catalog (37) to assess the potential of sub-network function through the identification of significant SNP-trait associations for every gene in each sub-network. We hypothesized that mutations within gene subsets that comprise each sub-network, as exemplified by SNP-trait associations from GWAS, were determined to be relevant to ketamine efficacy and adverse events and, as such, might provide further insight into the normal, unimpaired function of the various sub-networks. 


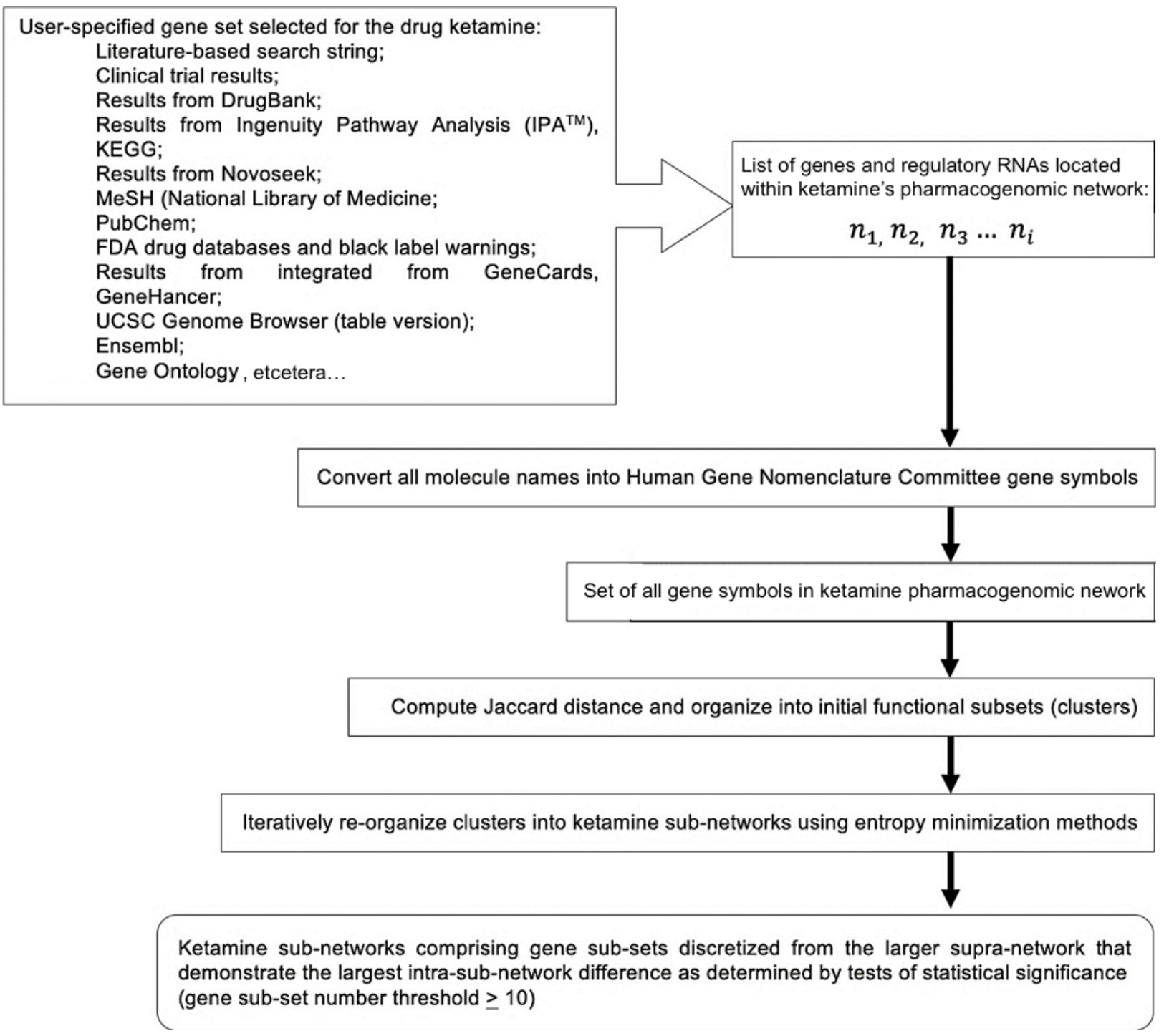

Figure 9. Iterative gene set optimization workflow. This iterative gene set optimization executable differs from gene set enrichment methods, by not only combining different mathematical methods, but also not acting in a hierarchal manner ranking genes as in threshold-dependent methods until the output, and this iterative gene set optimization does not rely on comparisons of experimental results, such as in whole-distribution tests. Instead, the iterative gene set optimization groups genes or long noncoding RNAs using the Jaccard distance to first measure the similarity between two genes or long noncoding RNAs based on the dissimilarity of user-selected terms, where the Jaccard distance is as the ratio of the size of the symmetric difference Gene $A$ $\Delta$ Gene $B=A \cap B-A \cup B$ to the union. This is extensible into clusters of related dissimilar gene names. A drug network server then automatically sorts these sets, or using user-defined numbers of clusters, into subsets of clustered subsets of functionally related genes using a minimal entropy sorting algorithm, such as the COOLCAT algorithm (94). Following gene subset optimization using entropy minimization, the pharmacogenomic spatial network identification system may employ manual curation to assign efficacy, adverse event or functional mechanistic sub-networks based on known attributes of the drug's mechanism of actions under consideration. 


\section{Selection of candidate ketamine response SNPs}

Our pharmaco-informatics platform processes data with minimal human intervention to avoid inhouse bias. Human SNPs were selected and processed using a revised version of the bioinformatics pipeline that has been described in detail in previous publications (22-25). For the workflow used in this study, GWAS SNPs were used as reported. These SNPs included all variants from GWAS related to genes within the larger ketamine pharmacogenomic network including genes located in the composite sub-networks. These included both SNP signals significantly associated with disease risk and those associated with ketamine antidepressant response efficacy and dissociation, as well as other ketamine network and sub-network-associated SNPs from the published literature and clinical trials $(8,37)$. The SNP filter judged candidate ketamine network SNPs for putative causality using multiple, redundant machine learning algorithms (39-45). The 65,535 SNPs contained in the EBI-NHGRI GWAS catalog (37) were evaluated for the 110-putative ketamineresponse genes and regulatory RNAs contained in our sub-networks. Phenotypes that were defined by self-reporting, such as educational attainment, mathematical ability and intelligence, were not included. Phenotypes, including insomnia and neuroticism, were also not included as there are various interpretations of these psychiatric surrogate associations. Since a plethora of GWAS SNPs associated with schizophrenia and depression were found to be primary determinants of differences between the ketamine glutamate receptor sub-network and the ketamine neuroplasticity sub-network, we undertook to provide greater clarification of these broad-spectrum phenotypes into subtypes. Phenotypes including smoking status, alcohol and substance abuse, nausea, vomiting and migraine were included based on their relevance to the psychological features of patients or the mechanisms of action of ketamine and its enantiomers. The genotype- 
phenotype association annotations were examined for determination of differences between the ketamine glutamate receptor sub-network and the ketamine neuroplasticity sub-network.

Numerical scores from each algorithm are generated for each GWAS SNP and only in cases where each output scored the SNP as predicted to be causal in SK-N-SH cells and H1 cells, but not in HepG2 cells and PBMCs, were the SNPs retained for further analysis. These numerical scores for every SNP are shown in Supplementary Table 4 and Supplementary Table 5. The score of every predicted causal SNP was independently tested to determine if it differed significantly from the scores generated using 10 randomly selected GWAS SNPs for all human traits at $p \leq 5 \mathrm{E}-08$ listed in the EBI-NHGRI GWAS catalogue (34) using ANOVA. Only when the SNP met this criterion of significance, was it selected for further analysis. An example for the SNP rs12967143-G, an intragenic enhancer within the TCF4 gene, is shown in Figure 10.

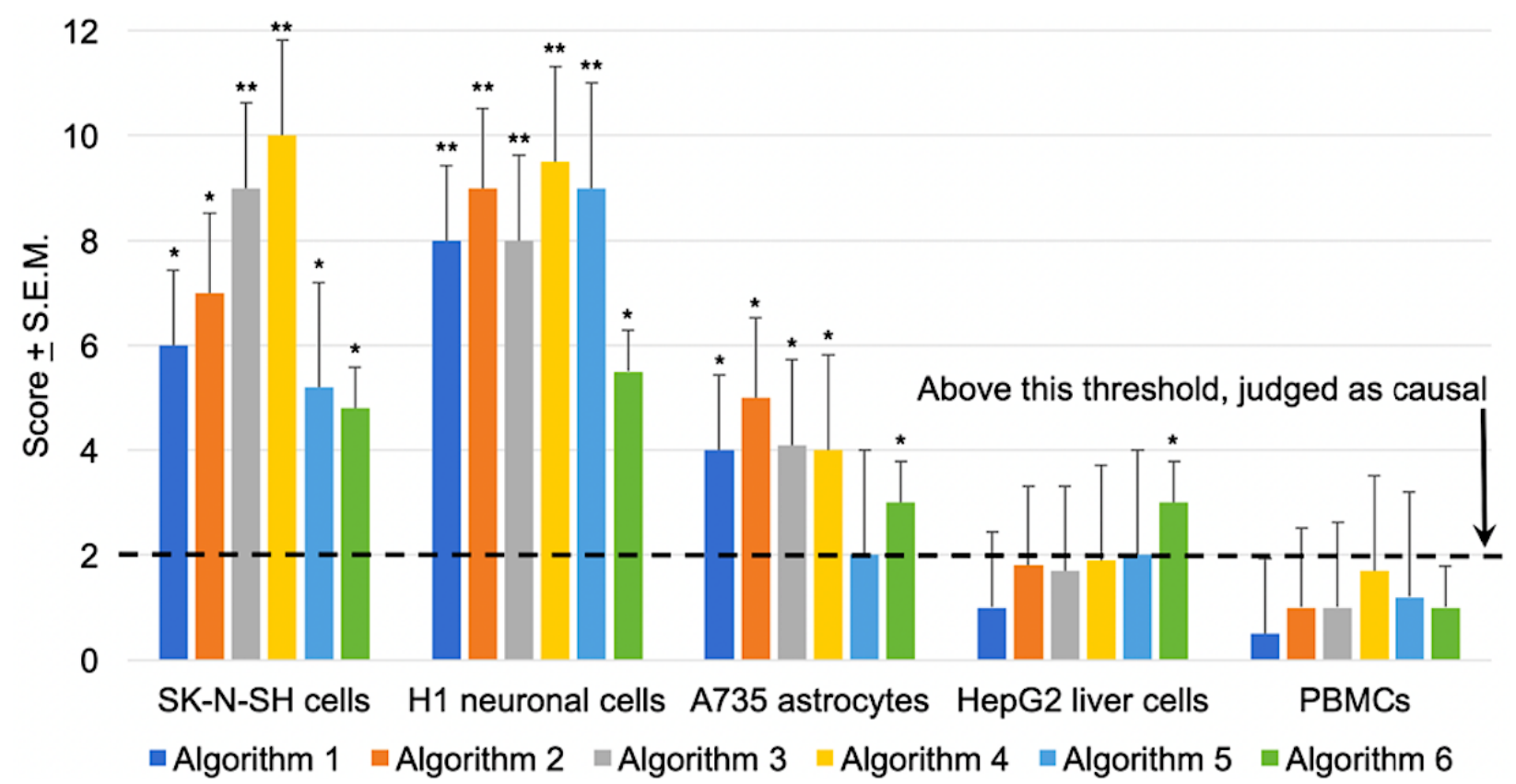

Figure 10. Results of significance testing of the SNP rs12967143-G, an intragenic enhancer located in the TCF4 gene, versus other GWAS SNPs as described using the numerical output from the machine learning algorithms used in the analysis. ${ }^{*} p \leq 0.05 ; * * p \leq 0.01$. 


\section{Annotation of enhancer-promoter pairs and chromatin contacts in neural cell lines and brain}

GWAS SNPs within the 2 different ketamine sub-networks were annotated by disease risk, psychiatric subtype, enhancer, promoter, superenhancer and enhancer RNA co-localization, enhancer promoter interactions determined by Hi-C chromatin interactions using public data sources. We used an advanced version of an adjustable bin mapping method (formerly called "HiC compiling with Genomic and Regulatory Elements and Empirical Normalization”(“HGREEN")) method in which candidate ketamine response SNPs judged as causal using machine learning were used to probe public sources of Hi-C data obtained from SK-N-SH, H1, and A735 cells. This approach was used to verify public data on the localization of enhancer-promoter pairs. The method employs non-fixed, adjustable binning analytic software, which provides much higher resolution for point-to-point mapping in squared human genome space than other methods. The adjustable bin mapping method maps ketamine SNPs to determine the distribution of TADs altered by various psychotropic drugs within the chromatin interactome and the cis- and trans-interactions of TADs containing pharmacogenomic SNPs for ketamine that were assessed in neuronal, astrocyte, hepatocyte cell lines and peripheral blood mononuclear cells.

To map genomic element contacts, this chromatin interaction method obtains a set of genomic loci and segments the set into bins of varying sizes. The method selects 2 sets of bins corresponding to the home TAD of the pharmacogenomic SNP and one of its contact TADs (e.g., a first set of bins corresponding to chromosome 1 and a second set of bins corresponding to chromosome 8) and places them in an $n \times m$ matrix (a squared genome area) to generate a set of bin pairs. Accordingly, the squared genome area may be of variable size and shape. In some run versions, both sets of bins are the same (e.g., each corresponding to chromosome 1). The chromatin 
interaction system identifies pairs of locations corresponding to paired end reads or other spatially interacting locations with bin pairs that contain them, i.e. wherein one of the bins contains one locus and the other bin contains the other locus, using a binary search tree. Then an interaction frequency is generated for each bin pair based on the genomic element contacts within the corresponding bin pair. The interaction frequencies are normalized per the density of pairwise contacts as a function of genomic distance within each bin pair. More specifically, the density of pairwise contacts as a function of genomic distance is generated using a normalized density function.

For a bin pair containing origin and target contact TADs, the density function is integrated over the squared genome area of the bin pair to determine an expected density for the bin pair. The expected density is then compared to the actual density for the bin pair (i.e., the number of pairwise contacts within the squared genome area of the bin pair) using the statistical test of BenjaminiHochberg false discovery rate (96). These generate a collection of enriched and depleted chromatin contacts in a manner adjusted for distance (and other features as appropriate), on a local and genomewide basis. The chromatin interaction system then provides indications of the bin pairs having, for example, enriched or depleted contacts for display on a user interface. By using variable bin sizes, the chromatin interaction system enables adjustable Hi-C bin mapping, regardless of bin length.

\section{Neuroanatomical localization of enhancer sub-networks}

First, comparison was made between the expression patterns of genes within the ketamine subnetworks with a consensus heatmap of the drug's rapid antidepressant response map derived from 
functional neuroimaging, as previously described (Supplementary Figure 1). Second, we evaluated the 108 non-overlapping GWAS SNPs annotated for their putative regulatory function as enhancers, promoters, superenhancers and splice variants, and then used a variety of sources of Hi-C data for neuroanatomical assignment to human brain regions including the amygdala, anterior caudate, cerebellum, cingulate cortex, frontal cortex, hippocampus, nucleus accumbens and the occipital cortex from Hi-C data $(46,61,62,74)$.

\section{Whole genome, Hi-C mapping performed using disease risk and pharmacogenomic SNPs}

In addition to the adjustable bin mapping method developed in our laboratory, we used a local instance of the HiGlass software for rapid identification of the cis- and trans-interactions of all of the 108 non-overlapping GWAS SNPs shown in Supplementary Table 4 and Supplementary Table 5 (74). This client-server software converts single resolution 1D linear human genome into multi-resolution formats that can be interactively searched in $\mathrm{Hi}-\mathrm{C}$ from neuronal cells and tissues, and other sources, for spatial chromatin contacts. This software was used to generate a set of spatial interactions for the ketamine glutamate receptor sub-network and the ketamine neuroplasticity subnetwork. In excitatory human glutamate neurons, the following have both cis- and transinteractions with all members of this gene set: ATFIP2, CACNA1C, CACNG2, CHNRNA3, DRD2, GRIN1, GRIN2A, GRIN2B, NOS1 and SETDB1, compared to other tissues or cell lines. In neuronal cell lines, the following genes had both cis- and trans-interactions with each other: TCF4, DCC, and GRM5, compared to other tissues or cell lines. Examples of gene pair trans interactions within and between the sub-networks is shown in Figure 7, and local cis interactions are shown for the GRIN2A and GRIN2B loci in Figure 8. 


\section{References}

1. P. Cuijpers, The challenges of improving treatments for depression. Jama 320, 2529-2530 (2018).

2. K. Jonkman, A. Dahan, T. van de Donk, L. Aarts, M. Niesters, M. van Velzen, Ketamine for pain [version 1; peer review: 2 approved]. F1000Research 6, (2017).

3. J. F. Greden, M. B. Riba, M. G. McInnis, U. M. C. D. Center, Treatment Resistant Depression: A Roadmap for Effective Care. (American Psychiatric Publishing, 2011).

4. V. A. Canady, FDA panel endorses ketamine nasal spray for depression. Mental Health Weekly 29, 6-7 (2019).

5. R. Machado-Vieira, G. Salvadore, N. Diazgranados, C. A. Zarate, Jr., Ketamine and the next generation of antidepressants with a rapid onset of action. Pharmacology \& therapeutics 123, 143-150 (2009).

6. M. J. Niciu, I. D. Henter, D. A. Luckenbaugh, C. A. Zarate, Jr., D. S. Charney, Glutamate receptor antagonists as fast-acting therapeutic alternatives for the treatment of depression: ketamine and other compounds. Annual review of pharmacology and toxicology 54, 119-139 (2014).

7. E. J. Daly, J. B. Singh, M. Fedgchin, K. Cooper, P. Lim, R. C. Shelton, M. E. Thase, A. Winokur, L. Van Nueten, H. Manji, W. C. Drevets, Efficacy and safety of intranasal esketamine adjunctive to oral antidepressant therapy in treatment-resistant depression: A randomized clinical trial. JAMA psychiatry 75, 139-148 (2018).

8. P. Zanos, R. Moaddel, P. J. Morris, L. M. Riggs, J. N. Highland, P. Georgiou, E. F. R. Pereira, E. X. Albuquerque, C. J. Thomas, C. A. Zarate, Jr., T. D. Gould, Ketamine and ketamine metabolite pharmacology: Insights into therapeutic mechanisms. Pharmacological reviews 70, 621-660 (2018).

$9 . \quad$ R. N. Moda-Sava, M. H. Murdock, P. K. Parekh, R. N. Fetcho, B. S. Huang, T. N. Huynh, J. Witztum, D. C. Shaver, D. L. Rosenthal, E. J. Alway, K. Lopez, Y. Meng, L. Nellissen, L. Grosenick, T. A. Milner, K. Deisseroth, H. Bito, H. Kasai, C. Liston, Sustained rescue of prefrontal circuit dysfunction by antidepressantinduced spine formation. Science 364, (2019).

10. J. M. Li, L. L. Liu, W. J. Su, B. Wang, T. Zhang, Y. Zhang, C. L. Jiang, Ketamine may exert antidepressant effects via suppressing NLRP3 inflammasome to upregulate AMPA receptors. Neuropharmacology 146, 149-153 (2019).

11. X. Chen, S. Shu, D. A. Bayliss, HCN1 channel subunits are a molecular substrate for hypnotic actions of ketamine. The Journal of neuroscience : the official journal of the Society for Neuroscience 29, 600-609 (2009).

12. M. F. Ho, C. Correia, J. N. Ingle, R. Kaddurah-Daouk, L. Wang, S. H. Kaufmann, R. M. Weinshilboum, Ketamine and ketamine metabolites as novel estrogen receptor ligands: Induction of cytochrome P450 and AMPA glutamate receptor gene expression. Biochemical pharmacology 152, 279-292 (2018).

13. J. Li, F.F. Chen, X.D. Chen, C. Zhou, C. Inhibition of HCN1 channels by ketamine accounts for its antidepressant actions. Journal of Sichuan University. Medical science edition 45, 888-92 (2014).

14. D. M. McMillan, R. F. Tyndale, CYP-mediated drug metabolism in the brain impacts drug response. Pharmacology \& therapeutics 184, 189-200 (2018).

15. W. Guo, R. Machado-Vieira, S. Mathew, J. W. Murrough, D. S. Charney, M. Grunebaum, M. A. Oquendo, B. Kadriu, N. Akula, I. Henter, P. Yuan, K. Merikangas, W. Drevets, M. Furey, J. J. Mann, F. J. McMahon, C. A. Zarate, Jr., Y. Y. Shugart, Exploratory genome-wide association analysis of response to ketamine and a polygenic analysis of response to scopolamine in depression. Translational psychiatry 8, 280 (2018).

16. E. C. Sales, E. L. Heckman, T. L. Warren, C. Q. Doe, Regulation of subcellular dendritic synapse specificity by axon guidance cues. eLife $\mathbf{8}$, (2019).

17. N. Li, B. Lee, R. J. Liu, M. Banasr, J. M. Dwyer, M. Iwata, X. Y. Li, G. Aghajanian, R. S. Duman, mTORdependent synapse formation underlies the rapid antidepressant effects of NMDA antagonists. Science 329, 959-964 (2010).

18. C. S. Jernigan, D. B. Goswami, M. C. Austin, A. H. Iyo, A. Chandran, C. A. Stockmeier, B. Karolewicz, The mTOR signaling pathway in the prefrontal cortex is compromised in major depressive disorder. Progress in neuro-psychopharmacology \& biological psychiatry 35, 1774-1779 (2011).

19. G. Laje, N. Lally, D. Mathews, N. Brutsche, A. Chemerinski, N. Akula, B. Kelmendi, A. Simen, F. J. McMahon, G. Sanacora, C. Zarate, Jr., Brain-derived neurotrophic factor Val66Met polymorphism and antidepressant efficacy of ketamine in depressed patients. Biological psychiatry 72, e27-28 (2012). 
20. G. M. Murphy, Jr., J. E. Sarginson, H. S. Ryan, R. O'Hara, A. F. Schatzberg, L. C. Lazzeroni, BDNF and CREB1 genetic variants interact to affect antidepressant treatment outcomes in geriatric depression. Pharmacogenetics and genomics 23, 301-313 (2013).

21. R. S. Duman, N. Li, R. J. Liu, V. Duric, G. Aghajanian, Signaling pathways underlying the rapid antidepressant actions of ketamine. Neuropharmacology 62, 35-41 (2012).

22. G. A. Higgins, A. M. Williams, A. S. Ade, H. B. Alam, B. D. Athey, Druggable transcriptional networks in the human neurogenic epigenome. Pharmacological reviews 71, 520-538 (2019).

23. G. A. Higgins, A. Allyn-Feuer, B. D. Athey, Epigenomic mapping and effect sizes of noncoding variants associated with psychotropic drug response. Pharmacogenomics 16, 1565-1583 (2015).

24. G. A. Higgins, A. Allyn-Feuer, E. Barbour, B. D. Athey, A glutamatergic network mediates lithium response in bipolar disorder as defined by epigenome pathway analysis. Pharmacogenomics 16, 1547-1563 (2015).

25. A. A. Kalinin, G. A. Higgins, N. Reamaroon, S. Soroushmehr, A. Allyn-Feuer, I. D. Dinov, K. Najarian, B. D. Athey, Deep learning in pharmacogenomics: from gene regulation to patient stratification. Pharmacogenomics 19, 629-650 (2018).

26. S. Dong, A. P. Boyle, Predicting functional variants in enhancer and promoter elements using RegulomeDB. Human mutation 40, 1292-1298 (2019).

27. M. T. Maurano, R. Humbert, E. Rynes, R. E. Thurman, E. Haugen, H. Wang, A. P. Reynolds, R. Sandstrom, H. Qu, J. Brody, A. Shafer, F. Neri, K. Lee, T. Kutyavin, S. Stehling-Sun, A. K. Johnson, T. K. Canfield, E. Giste, M. Diegel, D. Bates, R. S. Hansen, S. Neph, P. J. Sabo, S. Heimfeld, A. Raubitschek, S. Ziegler, C. Cotsapas, N. Sotoodehnia, I. Glass, S. R. Sunyaev, R. Kaul, J. A. Stamatoyannopoulos, Systematic localization of common disease-associated variation in regulatory DNA. Science 337, 1190-1195 (2012).

28. S. Onengut-Gumuscu, W. M. Chen, O. Burren, N. J. Cooper, A. R. Quinlan, J. C. Mychaleckyj, E. Farber, J. K. Bonnie, M. Szpak, E. Schofield, P. Achuthan, H. Guo, M. D. Fortune, H. Stevens, N. M. Walker, L. D. Ward, A. Kundaje, M. Kellis, M. J. Daly, J. C. Barrett, J. D. Cooper, P. Deloukas, J. A. Todd, C. Wallace, P. Concannon, S. S. Rich, Fine mapping of type 1 diabetes susceptibility loci and evidence for colocalization of causal variants with lymphoid gene enhancers. Nature genetics 47, 381-386 (2015).

29. Y. G. Tak, P. J. Farnham, Making sense of GWAS: using epigenomics and genome engineering to understand the functional relevance of SNPs in non-coding regions of the human genome. Epigenetics \& chromatin $\mathbf{8}$, 57 (2015).

30. S. C. Parker, M. L. Stitzel, D. L. Taylor, J. M. Orozco, M. R. Erdos, J. A. Akiyama, K. L. van Bueren, P. S. Chines, N. Narisu, B. L. Black, A. Visel, L. A. Pennacchio, F. S. Collins, Chromatin stretch enhancer states drive cell-specific gene regulation and harbor human disease risk variants. Proceedings of the National Academy of Sciences of the United States of America 110, 17921-17926 (2013).

31. P. Collas, T. M. Liyakat Ali, A. Brunet, T. Germier, Finding friends in the crowd: Three-dimensional cliques of topological genomic domains. Frontiers in genetics 10, 602 (2019).

32. A. Kramer, J. Green, J. Pollard, Jr., S. Tugendreich, Causal analysis approaches in Ingenuity Pathway Analysis. Bioinformatics (Oxford, England) 30, 523-530 (2014).

33. D. Szklarczyk, A. L. Gable, D. Lyon, A. Junge, S. Wyder, J. Huerta-Cepas, M. Simonovic, N. T. Doncheva, J. H. Morris, P. Bork, L. J. Jensen, C. V. Mering, STRING v11: protein-protein association networks with increased coverage, supporting functional discovery in genome-wide experimental datasets. Nucleic Acids Res 47, D607-d613 (2019).

34. H. Mi, A. Muruganujan, D. Ebert, X. Huang, P. D. Thomas, PANTHER version 14: more genomes, a new PANTHER GO-slim and improvements in enrichment analysis tools. Nucleic Acids Res 47, D419-d426 (2019).

35. M. Kanehisa, Y. Sato, M. Furumichi, K. Morishima, M. Tanabe, New approach for understanding genome variations in KEGG. Nucleic Acids Res 47, D590-d595 (2019).

36. J. R. Dixon, S. Selvaraj, F. Yue, A. Kim, Y. Li, Y. Shen, M. Hu, J. S. Liu, B. Ren, Topological domains in mammalian genomes identified by analysis of chromatin interactions. Nature 485, 376-380 (2012).

37. A. Buniello, J. A. L. MacArthur, M. Cerezo, L. W. Harris, J. Hayhurst, C. Malangone, A. McMahon, J. Morales, E. Mountjoy, E. Sollis, D. Suveges, O. Vrousgou, P. L. Whetzel, R. Amode, J. A. Guillen, H. S. Riat, S. J. Trevanion, P. Hall, H. Junkins, P. Flicek, T. Burdett, L. A. Hindorff, F. Cunningham, H. Parkinson, The NHGRI-EBI GWAS Catalog of published genome-wide association studies, targeted arrays and summary statistics 2019. Nucleic Acids Res 47, D1005-d1012 (2019).

38. G. Stelzer, N. Rosen, I. Plaschkes, S. Zimmerman, M. Twik, S. Fishilevich, T. I. Stein, R. Nudel, I. Lieder, Y. Mazor, S. Kaplan, D. Dahary, D. Warshawsky, Y. Guan-Golan, A. Kohn, N. Rappaport, M. Safran, D. 
Lancet, The GeneCards Suite: From Gene Data Mining to Disease Genome Sequence Analyses. Current protocols in bioinformatics 54, 1.30.31-31.30.33 (2016).

39. B. Yang, F. Liu, C. Ren, Z. Ouyang, Z. Xie, X. Bo, W. Shu, BiRen: predicting enhancers with a deeplearning-based model using the DNA sequence alone. Bioinformatics (Oxford, England) 33, 1930-1936 (2017).

$40 . \quad$ D. Lee, D. U. Gorkin, M. Baker, B. J. Strober, A. L. Asoni, A. S. McCallion, M. A. Beer, A method to predict the impact of regulatory variants from DNA sequence. Nature genetics 47, 955-961 (2015).

41. S. Li, R. V. Alvarez, R. Sharan, D. Landsman, I. Ovcharenko, Quantifying deleterious effects of regulatory variants. Nucleic Acids Res 45, 2307-2317 (2017).

42. D. Quang, X. Xie, DanQ: a hybrid convolutional and recurrent deep neural network for quantifying the function of DNA sequences. Nucleic Acids Res 44, e107 (2016).

43. D. R. Kelley, J. Snoek, J. L. Rinn, Basset: learning the regulatory code of the accessible genome with deep convolutional neural networks. Genome research 26, 990-999 (2016).

44. B. Han, M. Park, X. W. Chen, A Markov blanket-based method for detecting causal SNPs in GWAS. BMC bioinformatics 11 Suppl 3, S5 (2010).

45. G. E. Hoffman, J. Bendl, K. Girdhar, E. E. Schadt, P. Roussos, Functional interpretation of genetic variants using deep learning predicts impact on chromatin accessibility and histone modification. Nucleic Acids Res, (2019).

46. A. Allyn-Feuer, Thesis, University of Michigan, Ann Arbor, Michigan 48109 U.S.A. (2018).

47. L. Wright, S. M. Tobias, A. Hickman, Coding and documentation compliance for the ICD and DSM. (Routledge New York, 2017).

48. N. Rappaport, M. Twik, I. Plaschkes, R. Nudel, T. Iny Stein, J. Levitt, M. Gershoni, C. P. Morrey, M. Safran, D. Lancet, MalaCards: an amalgamated human disease compendium with diverse clinical and genetic annotation and structured search. Nucleic Acids Res 45, D877-d887 (2017).

49. A. Khan, X. Zhang, dbSUPER: a database of super-enhancers in mouse and human genome. Nucleic Acids Res 44, D164-171 (2016).

50. Y. Wei, S. Zhang, S. Shang, B. Zhang, S. Li, X. Wang, F. Wang, J. Su, Q. Wu, H. Liu, Y. Zhang, SEA: a super-enhancer archive. Nucleic Acids Res 44, D172-179 (2016).

51. S. Fishilevich, R. Nudel, N. Rappaport, R. Hadar, I. Plaschkes, T. Iny Stein, N. Rosen, A. Kohn, M. Twik, M. Safran, D. Lancet, D. Cohen, GeneHancer: genome-wide integration of enhancers and target genes in GeneCards. Database : the journal of biological databases and curation 2017, (2017).

52. R. Dreos, G. Ambrosini, R. Groux, R. Cavin Perier, P. Bucher, The eukaryotic promoter database in its 30th year: focus on non-vertebrate organisms. Nucleic Acids Res 45, D51-d55 (2017).

53. R. Umarov, H. Kuwahara, Y. Li, X. Gao, V. Solovyev, Promoter analysis and prediction in the human genome using sequence-based deep learning models. Bioinformatics (Oxford, England) 35, 2730-2737 (2019).

54. P. Belokopytova, E. Mozheiko, M. Nuriddinov, D. Fishman, V. Fishman, Quantitative prediction of enhancer-promoter interactions. bioRxiv, 541011 (2019).

55. Y. Murakawa, M. Yoshihara, H. Kawaji, M. Nishikawa, H. Zayed, H. Suzuki, C. Fantom, Y. Hayashizaki, Enhanced Identification of Transcriptional Enhancers Provides Mechanistic Insights into Diseases. Trends in genetics : TIG 32, 76-88 (2016).

56. F. Cunningham, P. Achuthan, W. Akanni, J. Allen, M. R. Amode, I. M. Armean, R. Bennett, J. Bhai, K. Billis, S. Boddu, C. Cummins, C. Davidson, K. J. Dodiya, A. Gall, C. G. Giron, L. Gil, T. Grego, L. Haggerty, E. Haskell, T. Hourlier, O. G. Izuogu, S. H. Janacek, T. Juettemann, M. Kay, M. R. Laird, I. Lavidas, Z. Liu, J. E. Loveland, J. C. Marugan, T. Maurel, A. C. McMahon, B. Moore, J. Morales, J. M. Mudge, M. Nuhn, D. Ogeh, A. Parker, A. Parton, M. Patricio, A. I. Abdul Salam, B. M. Schmitt, H. Schuilenburg, D. Sheppard, H. Sparrow, E. Stapleton, M. Szuba, K. Taylor, G. Threadgold, A. Thormann, A. Vullo, B. Walts, A. Winterbottom, A. Zadissa, M. Chakiachvili, A. Frankish, S. E. Hunt, M. Kostadima, N. Langridge, F. J. Martin, M. Muffato, E. Perry, M. Ruffier, D. M. Staines, S. J. Trevanion, B. L. Aken, A. D. Yates, D. R. Zerbino, P. Flicek, Ensembl 2019. Nucleic Acids Res 47, D745-d751 (2019).

57. M. Becker, T. Guadalupe, B. Franke, D. P. Hibar, M. E. Renteria, J. L. Stein, P. M. Thompson, C. Francks, S. C. Vernes, S. E. Fisher, Early developmental gene enhancers affect subcortical volumes in the adult human brain. Human brain mapping 37, 1788-1800 (2016).

58. L. Chen, A. E. Fish, J. A. Capra, Deep learning reveals evolutionary conservation and divergence of sequence properties underlying gene regulatory enhancers across mammals. bioRxiv, 110676 (2018). 
59. A. R. Forrest, H. Kawaji, M. Rehli, J. K. Baillie, M. J. de Hoon, V. Haberle, T. Lassmann, I. V. Kulakovskiy, M. Lizio, M. Itoh, R. Andersson, C. J. Mungall, T. F. Meehan, S. Schmeier, N. Bertin, M. Jorgensen, E. Dimont, E. Arner, C. Schmidl, U. Schaefer, Y. A. Medvedeva, C. Plessy, M. Vitezic, J. Severin, C. Semple, Y. Ishizu, R. S. Young, M. Francescatto, I. Alam, D. Albanese, G. M. Altschuler, T. Arakawa, J. A. Archer, P. Arner, M. Babina, S. Rennie, P. J. Balwierz, A. G. Beckhouse, S. Pradhan-Bhatt, J. A. Blake, A. Blumenthal, B. Bodega, A. Bonetti, J. Briggs, F. Brombacher, A. M. Burroughs, A. Califano, C. V. Cannistraci, D. Carbajo, Y. Chen, M. Chierici, Y. Ciani, H. C. Clevers, E. Dalla, C. A. Davis, M. Detmar, A. D. Diehl, T. Dohi, F. Drablos, A. S. Edge, M. Edinger, K. Ekwall, M. Endoh, H. Enomoto, M. Fagiolini, L. Fairbairn, H. Fang, M. C. Farach-Carson, G. J. Faulkner, A. V. Favorov, M. E. Fisher, M. C. Frith, R. Fujita, S. Fukuda, C. Furlanello, M. Furino, J. Furusawa, T. B. Geijtenbeek, A. P. Gibson, T. Gingeras, D. Goldowitz, J. Gough, S. Guhl, R. Guler, S. Gustincich, T. J. Ha, M. Hamaguchi, M. Hara, M. Harbers, J. Harshbarger, A. Hasegawa, Y. Hasegawa, T. Hashimoto, M. Herlyn, K. J. Hitchens, S. J. Ho Sui, O. M. Hofmann, I. Hoof, F. Hori, L. Huminiecki, K. Iida, T. Ikawa, B. R. Jankovic, H. Jia, A. Joshi, G. Jurman, B. Kaczkowski, C. Kai, K. Kaida, A. Kaiho, K. Kajiyama, M. Kanamori-Katayama, A. S. Kasianov, T. Kasukawa, S. Katayama, S. Kato, S. Kawaguchi, H. Kawamoto, Y. I. Kawamura, T. Kawashima, J. S. Kempfle, T. J. Kenna, J. Kere, L. M. Khachigian, T. Kitamura, S. P. Klinken, A. J. Knox, M. Kojima, S. Kojima, N. Kondo, H. Koseki, S. Koyasu, S. Krampitz, A. Kubosaki, A. T. Kwon, J. F. Laros, W. Lee, A. Lennartsson, K. Li, B. Lilje, L. Lipovich, A. Mackay-Sim, R. Manabe, J. C. Mar, B. Marchand, A. Mathelier, N. Mejhert, A. Meynert, Y. Mizuno, D. A. de Lima Morais, H. Morikawa, M. Morimoto, K. Moro, E. Motakis, H. Motohashi, C. L. Mummery, M. Murata, S. Nagao-Sato, Y. Nakachi, F. Nakahara, T. Nakamura, Y. Nakamura, K. Nakazato, E. van Nimwegen, N. Ninomiya, H. Nishiyori, S. Noma, S. Noma, T. Noazaki, S. Ogishima, N. Ohkura, H. Ohimiya, H. Ohno, M. Ohshima, M. Okada-Hatakeyama, Y. Okazaki, V. Orlando, D. A. Ovchinnikov, A. Pain, R. Passier, M. Patrikakis, H. Persson, S. Piazza, J. G. Prendergast, O. J. Rackham, J. A. Ramilowski, M. Rashid, T. Ravasi, P. Rizzu, M. Roncador, S. Roy, M. B. Rye, E. Saijyo, A. Sajantila, A. Saka, S. Sakaguchi, M. Sakai, H. Sato, S. Savvi, A. Saxena, C. Schneider, E. A. Schultes, G. G. Schulze-Tanzil, A. Schwegmann, T. Sengstag, G. Sheng, H. Shimoji, Y. Shimoni, J. W. Shin, C. Simon, D. Sugiyama, T. Sugiyama, M. Suzuki, N. Suzuki, R. K. Swoboda, P. A. t Hoen, M. Tagami, N. Takahashi, J. Takai, H. Tanaka, H. Tatsukawa, Z. Tatum, M. Thompson, H. Toyodo, T. Toyoda, E. Valen, M. van de Wetering, L. M. van den Berg, R. Verado, D. Vijayan, I. E. Vorontsov, W. W. Wasserman, S. Watanabe, C. A. Wells, L. N. Winteringham, E. Wolvetang, E. J. Wood, Y. Yamaguchi, M. Yamamoto, M. Yoneda, Y. Yonekura, S. Yoshida, S. E. Zabierowski, P. G. Zhang, X. Zhao, S. Zucchelli, K. M. Summers, H. Suzuki, C. O. Daub, J. Kawai, P. Heutink, W. Hide, T. C. Freeman, B. Lenhard, V. B. Bajic, M. S. Taylor, V. J. Makeev, A. Sandelin, D. A. Hume, P. Carninci, Y. Hayashizaki, A promoter-level mammalian expression atlas. Nature 507, 462-470 (2014).

$60 . \quad$ C. C. Hon, J. A. Ramilowski, J. Harshbarger, N. Bertin, O. J. Rackham, J. Gough, E. Denisenko, S. Schmeier, T. M. Poulsen, J. Severin, M. Lizio, H. Kawaji, T. Kasukawa, M. Itoh, A. M. Burroughs, S. Noma, S. Djebali, T. Alam, Y. A. Medvedeva, A. C. Testa, L. Lipovich, C. W. Yip, I. Abugessaisa, M. Mendez, A. Hasegawa, D. Tang, T. Lassmann, P. Heutink, M. Babina, C. A. Wells, S. Kojima, Y. Nakamura, H. Suzuki, C. O. Daub, M. J. de Hoon, E. Arner, Y. Hayashizaki, P. Carninci, A. R. Forrest, An atlas of human long non-coding RNAs with accurate 5' ends. Nature 543, 199-204 (2017).

61. X. Zheng, Y. Zheng, CscoreTool: fast Hi-C compartment analysis at high resolution. Bioinformatics (Oxford, England) 34, 1568-1570 (2018).

62. M. Forcato, C. Nicoletti, K. Pal, C. M. Livi, F. Ferrari, S. Bicciato, Comparison of computational methods for Hi-C data analysis. Nat Methods 14, 679-685 (2017).

63. R. Birnbaum, A. E. Jaffe, Q. Chen, T. M. Hyde, J. E. Kleinman, D. R. Weinberger, Investigation of the prenatal expression patterns of 108 schizophrenia-associated genetic loci. Biological psychiatry 77, e43-51 (2015).

64. Human genomics. The Genotype-Tissue Expression (GTEx) pilot analysis: multitissue gene regulation in humans. Science 348, 648-660 (2015).

65. The NCBI Handbook [Internet]. (National Center for Biotechnology Information, Bethesda, Maryland U.S.A., ed. 2nd Edition, 2013-).

66. I. Lee, U.M. Blom, P.I Wang, J.E. Shim, E.M. Marcotte, Prioritizing candidate disease genes by networkbased boosting of genome-wide association data. Genome research 21, 1109-1121 (2011).

67. M. J. Hawrylycz, E. S. Lein, A. L. Guillozet-Bongaarts, E. H. Shen, L. Ng, J. A. Miller, L. N. van de Lagemaat, K. A. Smith, A. Ebbert, Z. L. Riley, C. Abajian, C. F. Beckmann, A. Bernard, D. Bertagnolli, A. F. Boe, P. M. Cartagena, M. M. Chakravarty, M. Chapin, J. Chong, R. A. Dalley, B. David Daly, C. Dang, 
S. Datta, N. Dee, T. A. Dolbeare, V. Faber, D. Feng, D. R. Fowler, J. Goldy, B. W. Gregor, Z. Haradon, D. R. Haynor, J. G. Hohmann, S. Horvath, R. E. Howard, A. Jeromin, J. M. Jochim, M. Kinnunen, C. Lau, E. T. Lazarz, C. Lee, T. A. Lemon, L. Li, Y. Li, J. A. Morris, C. C. Overly, P. D. Parker, S. E. Parry, M. Reding, J. J. Royall, J. Schulkin, P. A. Sequeira, C. R. Slaughterbeck, S. C. Smith, A. J. Sodt, S. M. Sunkin, B. E. Swanson, M. P. Vawter, D. Williams, P. Wohnoutka, H. R. Zielke, D. H. Geschwind, P. R. Hof, S. M. Smith, C. Koch, S. G. N. Grant, A. R. Jones, An anatomically comprehensive atlas of the adult human brain transcriptome. Nature 489, 391-399 (2012).

68. M. Gartner, S. Aust, M. Bajbouj, Y. Fan, K. Wingenfeld, C. Otte, I. Heuser-Collier, H. Boker, J. Hattenschwiler, E. Seifritz, S. Grimm, M. Scheidegger, Functional connectivity between prefrontal cortex and subgenual cingulate predicts antidepressant effects of ketamine. European neuropsychopharmacology : the journal of the European College of Neuropsychopharmacology 29, 501-508 (2019).

69. C. G. Abdallah, L. A. Averill, K. A. Collins, P. Geha, J. Schwartz, C. Averill, K. E. DeWilde, E. Wong, A. Anticevic, C. Y. Tang, D. V. Iosifescu, D. S. Charney, J. W. Murrough, Ketamine treatment and global brain connectivity in major depression. Neuropsychopharmacology : official publication of the American College of Neuropsychopharmacology 42, 1210-1219 (2017).

70. J.A. Rinker, P.J. Mulholland, Promising pharmacogenetic targets for treating alcohol use disorder: evidence from preclinical models. Pharmacogenomics 18, 555-570 (2017).

71. R.T. Timms, I.A. Tchasovnikarova, R. Antrobus, G. Dougan, P.J. Lehner, P. J. (2016). ATF7IP-mediated stabilization of the histone methyltransferase SETDB1 is essential for heterochromatin formation by the HUSH complex. Cell reports 17, 653-659 (2016).

72. Z. Zhou, M. He, A.A Shah, Y. Wan, Insights into APC/C: from cellular function to diseases and therapeutics. Cell division 11, 9 (2016).

73. E.A. Kramár, L.Y. Chen, N.J. Brandon, C.S. Rex, F. Liu, C.M. Gall, G. Lynch, Cytoskeletal changes underlie estrogen's acute effects on synaptic transmission and plasticity. Journal of Neuroscience 29, 12982-12993 (2009).

74. P. Kerpedjiev, N. Abdennur, F. Lekschas, C. McCallum, K. Dinkla, H. Strobelt, J.M. Luber, S.B. Ouellette, A. Azhir, N. Kumar, J. Hwang, J., HiGlass: web-based visual exploration and analysis of genome interaction maps. Genome biology 19, 125 (2018).

75. M. Haeussler, A. S. Zweig, C. Tyner, M. L. Speir, K. R. Rosenbloom, B. J. Raney, C. M. Lee, B. T. Lee, A. S. Hinrichs, J. N. Gonzalez, D. Gibson, M. Diekhans, H. Clawson, J. Casper, G. P. Barber, D. Haussler, R. M. Kuhn, W. J. Kent, The UCSC Genome Browser database: 2019 update. Nucleic Acids Res 47, D853-d858 (2019).

76. G. Z. Reus, F. G. Vieira, H. M. Abelaira, M. Michels, D. B. Tomaz, M. A. dos Santos, A. S. Carlessi, M. V. Neotti, B. I. Matias, J. R. Luz, F. Dal-Pizzol, J. Quevedo, MAPK signaling correlates with the antidepressant effects of ketamine. Journal of psychiatric research 55, 15-21 (2014).

77. Y. Shang, Y. Wu, S. Yao, X. Wang, D. Feng, W. Yang, Protective effect of erythropoietin against ketamineinduced apoptosis in cultured rat cortical neurons: involvement of PI3K/Akt and GSK-3 beta pathway. Apoptosis : an international journal on programmed cell death 12, 2187-2195 (2007).

78. K. L. P. Garcia, A. D. Le, R. F. Tyndale, Brain CYP2B induction can decrease nicotine levels in the brain. Addiction biology 22, 1257-1266 (2017).

79. Q. Liu, C. Chen, A. Gao, H.H. Tong, L. Xie, VariFunNet, an integrated multiscale modeling framework to study the effects of rare non-coding variants in genome-wide association studies: Applied to Alzheimer's disease. In 2017 IEEE International Conference on Bioinformatics and Biomedicine (BIBM) (pp. 21772182). IEEE (2017).

80. L. Micheli, M. Ceccarelli, G. D'Andrea, F. Tirone, Depression and adult neurogenesis: Positive effects of the antidepressant fluoxetine and of physical exercise. Brain research bulletin 143, 181-193 (2018).

81. S. J. Oh, J. Cheng, J. H. Jang, J. Arace, M. Jeong, C. H. Shin, J. Park, J. Jin, P. Greengard, Y. S. Oh, Hippocampal mossy cell involvement in behavioral and neurogenic responses to chronic antidepressant treatment. Molecular psychiatry, (2019).

82. P. Arnstein, M. Caudill, C. L. Mandle, A. Norris, R. Beasley, Self efficacy as a mediator of the relationship between pain intensity, disability and depression in chronic pain patients. Pain 80, 483-491 (1999).

83. M. A. Peltoniemi, N. M. Hagelberg, K. T. Olkkola, T. I. Saari, Ketamine: A review of clinical pharmacokinetics and pharmacodynamics in anesthesia and pain therapy. Clinical pharmacokinetics $\mathbf{5 5}$, 1059-1077 (2016).

84. Gerard Sanacora, M.D. , and, Rachel Katz, M.D., Ketamine: A review for clinicians. FOCUS 16, $243-250$ (2018). 
85. J. de Leon, F. J. Diaz, A meta-analysis of worldwide studies demonstrates an association between schizophrenia and tobacco smoking behaviors. Schizophrenia research 76, 135-157 (2005).

86. A. Hunter, R. Murray, L. Asher, J. Leonardi-Bee, The effects of tobacco smoking, and prenatal tobacco smoke exposure, on risk of schizophrenia: a systematic review and meta-analysis. Nicotine \& tobacco research : official journal of the Society for Research on Nicotine and Tobacco, (2018).

87. J. G. Scott, L. Matuschka, S. Niemela, J. Miettunen, B. Emmerson, A. Mustonen, Evidence of a Causal Relationship Between Smoking Tobacco and Schizophrenia Spectrum Disorders. Frontiers in psychiatry 9 , 607 (2018).

88. Y. Zhou, M. Ingelman-Sundberg, V. M. Lauschke, Worldwide Distribution of Cytochrome P450 Alleles: A Meta-analysis of Population-scale Sequencing Projects. Clinical pharmacology and therapeutics 102, 688700 (2017).

89. A. J. Bloom, M. Martinez, L. S. Chen, L. J. Bierut, S. E. Murphy, A. Goate, CYP2B6 non-coding variation associated with smoking cessation is also associated with differences in allelic expression, splicing, and nicotine metabolism independent of common amino-acid changes. PloS one 8, e79700 (2013).

90. Y. Li, J. K. Coller, M. R. Hutchinson, K. Klein, U. M. Zanger, N. J. Stanley, A. D. Abell, A. A. Somogyi, The CYP2B6*6 allele significantly alters the N-demethylation of ketamine enantiomers in vitro. Drug metabolism and disposition: the biological fate of chemicals 41, 1264-1272 (2013).

91. Y. Li, K. A. Jackson, B. Slon, J. R. Hardy, M. Franco, L. William, P. Poon, J. K. Coller, M. R. Hutchinson, D. C. Currow, A. A. Somogyi, CYP2B $6 * 6$ allele and age substantially reduce steady-state ketamine clearance in chronic pain patients: impact on adverse effects. British journal of clinical pharmacology 80, 276-284 (2015).

92. D. P. Herzog, G. Wegener, K. Lieb, M. B. Muller, G. Treccani, Decoding the mechanism of action of rapidacting antidepressant treatment strategies: Does gender matter? International journal of molecular sciences 20, (2019).

93. D.S. Wishart, Y.D. Feunang, A.C. Guo, E.J. Lo, A. Marcu, J.R. Grant, T. Sajed, D. Johnson, C. Li, Z. Sayeeda, N. Assempour, N., DrugBank 5.0: a major update to the DrugBank database for 2018. Nucleic acids research, 46, D1074-D1082 (2017).

94. O. Ursu, J. Holmes, C.G. Bologa, J.J. Yang, S.L. Mathias, V. Stathias, D.T. Nguyen, S. Schürer, T. Oprea, DrugCentral 2018: an update. Nucleic acids research, 47, D963-D970 (2018).

95. D.Y.L. Barbará, J. Couto, COOLCAT: an entropy-based algorithm for categorical clustering. In Proceedings of the eleventh international conference on Information and knowledge management, pp. 582-589. ACM (2002).

96. D. Thissen, L. Steinberg, D. Kuang, Quick and easy implementation of the Benjamini-Hochberg procedure for controlling the false positive rate in multiple comparisons. Journal of educational and behavioral statistics 27, 77-83 (2002). 


\section{SUPPLEMENT}

\section{Ketamine Pharmacogenomic Network in Human Brain Contains Sub-Networks Associated with Glutamate Neurotransmission and with Neuroplasticity}

Authors: Gerald A. Higgins ${ }^{1,2}$, Samuel A. Handelman ${ }^{3}$, Ari Allyn-Feuer ${ }^{1} \uparrow$, Alex S. Ade ${ }^{1,2}$, James S. Burns ${ }^{2}$, Gilbert S. Omenn ${ }^{1,3,4,5}$, Brian D. Athey ${ }^{1,2,6 *}$

\section{Affiliations:}

${ }^{1}$ Department of Computational Medicine and Bioinformatics, University of Michigan Medical School, Ann Arbor, MI 48109, USA.

${ }^{2}$ Phenomics Health Inc., Ann Arbor, MI 48109, USA.

${ }^{3}$ Department of Internal Medicine, University of Michigan Medical School, Ann Arbor, MI 48109, USA.

${ }^{4}$ School of Public Health, University of Michigan, Ann Arbor, MI 48109, USA.

${ }^{5}$ Department of Human Genetics, University of Michigan Medical School, Ann Arbor, MI 48109, USA.

${ }^{6}$ Department of Psychiatry, University of Michigan Medical School, Ann Arbor, MI 48109, USA.

*Corresponding author: Email: bleu@med.umich.edu (B.D.A.)

$\uparrow$ Current address: GlaxoSmithKline, King of Prussia, PA 19406, USA.

\section{Table of Contents}

Supplementary Table 1: Functional neuroimaging studies used to build consensus map ........45

Supplementary Table 2. Ketamine sub-network gene symbols

Supplementary Table 3. Ketamine binding affinity studies.

Supplementary Figure 1. Consensus heatmap of gene expression and neuroimaging results ..51

Supplementary Figure 2. In situ hybridization of ketamine PD targets

Supplementary Table 4. GWAS SNPs from the ketamine glutamate receptor sub-network....53

Supplementary Table 5. GWAS SNPs from the ketamine neuroplasticity sub-network .54 
Supplementary Table 1: Functional neuroimaging studies used to build consensus map:

\begin{tabular}{|c|c|c|c|c|}
\hline TITLE & PARTICIPANTS & $\begin{array}{l}\text { KETAMINE'S SITE(S) OF } \\
\text { ACTION }\end{array}$ & MOD. & PMID \\
\hline $\begin{array}{l}\text { Effects of sub-anesthetic doses of } \\
\text { ketamine on regional cerebral blood } \\
\text { flow, oxygen consumption, and blood } \\
\text { volume in humans }\end{array}$ & $\begin{array}{l}9 \text { healthy } \\
\text { controls }\end{array}$ & $\begin{array}{l}\text { Anterior cingulate cortex } \\
\text { (ACC) and prefrontal cortex } \\
\text { (PFC). Not recognized - } \\
\text { anterior caudate (AC) and } \\
\text { nucleus accumbens (NA). }\end{array}$ & PET & 12960545 \\
\hline $\begin{array}{l}\text { Effects of ketamine on anterior } \\
\text { cingulate glutamate metabolism in } \\
\text { healthy humans: a } 4-T \text { proton MRS } \\
\text { study }\end{array}$ & $\begin{array}{l}10 \text { healthy } \\
\text { controls }\end{array}$ & $\begin{array}{l}\text { Anterior cingulate cortex } \\
(A C C) \text {. }\end{array}$ & $\begin{array}{l}1 \mathrm{H}- \\
\text { MRS }\end{array}$ & 15677610 \\
\hline $\begin{array}{l}\text { Increased anterior cingulate } \\
\text { cortical activity in } \\
\text { response to fearful faces: A } \\
\text { neurophysiological } \\
\text { biomarker that predicts } \\
\text { rapid antidepressant } \\
\text { response to ketamine }\end{array}$ & $\begin{array}{l}11 \text { healthy } \\
\text { controls and } 11 \\
\text { drug-free } \\
\text { patients } \\
\text { diagnosed with } \\
\text { MDD }\end{array}$ & $\begin{array}{l}\text { Patients with MDD exhibited } \\
\text { increased activity in the } \\
\text { anterior cingulate cortex } \\
\text { (ACC) after pretreatment } \\
\text { with fearful faces versus } \\
\text { controls. Also, changes } \\
\text { observed in right amygdala } \\
\text { (AMY). }\end{array}$ & MEG & 18822408 \\
\hline $\begin{array}{l}\text { Anterior cingulate desynchronization } \\
\text { and functional connectivity with the } \\
\text { amygdala during a working memory } \\
\text { task predict rapid antidepressant } \\
\text { response to ketamine }\end{array}$ & $\begin{array}{l}15 \text { drug-free } \\
\text { patients } \\
\text { diagnosed with } \\
\text { MDD }\end{array}$ & $\begin{array}{l}\text { Subgenual anterior cingulate } \\
\text { cortex (ACC), supplementary } \\
\text { motor area (SMA) and } \\
\text { amygdala (AMY). }\end{array}$ & MEG & 20393460 \\
\hline $\begin{array}{l}\text { Ketamine decreases resting state } \\
\text { functional network connectivity in } \\
\text { healthy subjects: Implications for } \\
\text { antidepressant drug action }\end{array}$ & $\begin{array}{l}17 \text { healthy } \\
\text { controls }\end{array}$ & $\begin{array}{l}\text { Subgenual anterior cingulate } \\
\text { cortex (sgACC), dorsomedial } \\
\text { prefrontal cortex (PFC), }\end{array}$ & $\begin{array}{l}\text { fMRI } \\
\text { BOLD }\end{array}$ & 23049758 \\
\hline $\begin{array}{l}\text { Relationship of resting brain } \\
\text { hyperconnectivity and schizophrenia- } \\
\text { like symptoms produced by the NMDA } \\
\text { receptor antagonist ketamine in } \\
\text { humans }\end{array}$ & $\begin{array}{l}22 \text { healthy } \\
\text { controls; } \\
\text { Replication in } \\
\text { another } 12 \\
\text { healthy controls }\end{array}$ & $\begin{array}{l}\text { Ketamine administration } \\
\text { increased global brain } \\
\text { connectivity. } \\
\text { Psychotomimetic (negative) } \\
\text { effects following ketamine } \\
\text { administration were localized } \\
\text { to the nucleus accumbens } \\
\text { (NA) and anterior caudate } \\
\text { (AC). Positive symptoms } \\
\text { were associated with } \\
\text { changes in prefrontal cortex } \\
\text { (PFC), supplementary motor } \\
\text { area (SM), insula and } \\
\text { posterior cortex. }\end{array}$ & $\begin{array}{l}\text { rs- } \\
\text { fcMRI }\end{array}$ & 23337947 \\
\hline $\begin{array}{l}\text { Neural correlates of rapid } \\
\text { antidepressant response to ketamine in } \\
\text { treatment-resistant unipolar depression: } \\
\text { A preliminary PET study }\end{array}$ & $\begin{array}{l}20 \text { drug-free } \\
\text { patients } \\
\text { diagnosed with } \\
\text { TRD }\end{array}$ & $\begin{array}{l}\text { Anterior cingulate cortex } \\
\text { (ACC), prefrontal cortex } \\
\text { (PFC), amygdala (AMY) and } \\
\text { habenula. }\end{array}$ & PET & 23540908 \\
\hline $\begin{array}{l}\text { Neural correlates of rapid } \\
\text { antidepressant response to ketamine in } \\
\text { bipolar disorder }\end{array}$ & $\begin{array}{l}21 \text { patients with } \\
\text { bipolar } \\
\text { depression }\end{array}$ & $\begin{array}{l}\text { Sub-geniculate anterior } \\
\text { cingulate cortex (ACC), } \\
\text { supplementary motor area } \\
\text { (SMA), prefrontal cortex } \\
\text { (PFC). Also, unrecognized, } \\
\text { but included amygdala } \\
\text { (AMY), hippocampal } \\
\text { formation (HF), anterior } \\
\text { caudate (AC) and nucleus } \\
\text { accumbens (NA). }\end{array}$ & PET & 24103187 \\
\hline
\end{tabular}


bioRxiv preprint doi: https://doi.org/10.1101/2020.04.28.053587; this version posted April 30, 2020. The copyright holder for this preprint (which was not certified by peer review) is the author/funder, who has granted bioRxiv a license to display the preprint in perpetuity. It is made available under aCC-BY-NC-ND 4.0 International license.

\begin{tabular}{|c|c|c|c|c|}
\hline $\begin{array}{l}\text { Anti-anhedonic effect of ketamine and } \\
\text { its neural correlates in treatment- } \\
\text { resistant bipolar depression }\end{array}$ & $\begin{array}{l}36 \text { patients who } \\
\text { are treatment- } \\
\text { refractory } \\
\text { diagnosed with } \\
\text { bipolar disorder I } \\
\text { or II } \\
\end{array}$ & $\begin{array}{l}\text { Ketamine significantly } \\
\text { activated the dorsal anterior } \\
\text { cingulate cortex (dACC) and } \\
\text { the subcortex. }\end{array}$ & PET & 25313512 \\
\hline $\begin{array}{l}\text { Neural correlates of change in major } \\
\text { depressive disorder anhedonia } \\
\text { following open-label ketamine. }\end{array}$ & $\begin{array}{l}52 \text { patients } \\
\text { diagnosed with } \\
\text { TRD }\end{array}$ & $\begin{array}{l}\text { Supplementary motor area } \\
\text { (SMA), hippocampal } \\
\text { formation (HF), frontal gyrus } \\
\text { and orbitofrontal cortex } \\
\text { correlated with measures of } \\
\text { decreased anhedonia in } \\
\text { patients diagnosed with } \\
\text { MDD. Borderline } \\
\text { significance. }\end{array}$ & PET & 25691504 \\
\hline $\begin{array}{l}\text { A pilot in vivo proton magnetic } \\
\text { resonance spectroscopy study of amino } \\
\text { acid neurotransmitter response to } \\
\text { ketamine treatment of major depressive } \\
\text { disorder }\end{array}$ & $\begin{array}{l}11 \text { patients } \\
\text { diagnosed with } \\
\text { MDD }\end{array}$ & Prefrontal cortex (PFC). & $\begin{array}{l}1 \mathrm{H}- \\
\text { MRS }\end{array}$ & 26283639 \\
\hline $\begin{array}{l}\text { The effects of low-dose ketamine on the } \\
\text { prefrontal cortex and amygdala in } \\
\text { treatment-resistant depression: A } \\
\text { randomized controlled study }\end{array}$ & $\begin{array}{l}48 \text { patients } \\
\text { diagnosed with } \\
\text { TRD }\end{array}$ & $\begin{array}{l}\text { Prefrontal cortex (PFC), } \\
\text { amygdala (AMY) and } \\
\text { supplementary } \\
\text { motor area (SMA). }\end{array}$ & PET & 26821769 \\
\hline $\begin{array}{l}\text { Ketamine modulates } \\
\text { subgenual cingulate } \\
\text { connectivity with the memory-related } \\
\text { neural circuit-a mechanism of relevance } \\
\text { to resistant depression? }\end{array}$ & $\begin{array}{l}13 \text { healthy } \\
\text { controls }\end{array}$ & $\begin{array}{l}\text { Following ketamine infusion, } \\
\text { largest changes observed in } \\
\text { the connectivity of the } \\
\text { subgenual anterior cingulate } \\
\text { cortex (sgACC). }\end{array}$ & fMRI & 26925332 \\
\hline $\begin{array}{l}\text { Comparing the actions of } \\
\text { Lanicemine and ketamine in depression } \\
\text { : key role of the anterior cingulate }\end{array}$ & $\begin{array}{l}60 \text { un-medicated } \\
\text { patients } \\
\text { diagnosed with } \\
\text { MDD }\end{array}$ & $\begin{array}{l}\text { Intravenous infusion of } \\
\text { both ketamine and } \\
\text { Lanicemine gradually } \\
\text { increased activity in the } \\
\text { subgenual anterior } \\
\text { cingulate cortex (sgACC). }\end{array}$ & phMRI & 27133029 \\
\hline $\begin{array}{l}\text { Ketamine modulates hippocampal } \\
\text { neurochemistry and functional } \\
\text { connectivity - A combined magnetic } \\
\text { resonance spectroscopy and resting } \\
\text { state fMRI study in healthy volunteers }\end{array}$ & $\begin{array}{l}15 \text { healthy } \\
\text { controls }\end{array}$ & $\begin{array}{l}\text { Dorsomedial prefrontal } \\
\text { cortex (PFC) and anterior } \\
\text { cingulate cortex (ACC). } \\
\text { Psychosis severity produced } \\
\text { by ketamine was associated } \\
\text { with increased connectivity of } \\
\text { the hippocampal formation } \\
\text { (HF) with the middle } \\
\text { cingulate cortex, insula, } \\
\text { precuneus and superior } \\
\text { frontal gyrus. }\end{array}$ & $\begin{array}{l}\text { rs- } \\
\text { fcMRI; } \\
1 \mathrm{H}- \\
\text { MRS }\end{array}$ & 27480949 \\
\hline $\begin{array}{l}\text { Ketamine treatment and } \\
\text { global brain connectivity } \\
\text { in major depression }\end{array}$ & $\begin{array}{l}25 \text { healthy } \\
\text { controls and } 18 \\
\text { drug-free } \\
\text { patients } \\
\text { diagnosed with } \\
\text { MDD }\end{array}$ & $\begin{array}{l}\text { Subgenual anterior cingulate } \\
\text { cortex (sgACC), dorsolateral } \\
\text { prefrontal cortex and } \\
\text { dorsomedial prefrontal cortex } \\
\text { (PFC), anterior caudate } \\
\text { (AC), nucleus accumbens } \\
\text { (NA). }\end{array}$ & $\begin{array}{l}\text { rs- } \\
\text { fcMRI }\end{array}$ & 27604566 \\
\hline
\end{tabular}




\begin{tabular}{|c|c|c|c|c|}
\hline $\begin{array}{l}\text { The nucleus accumbens and ketamine } \\
\text { treatment in major depressive disorder }\end{array}$ & $\begin{array}{l}\text { The first cohort } \\
\text { was } 34 \text { patients } \\
\text { diagnosed with } \\
\text { MDD and } 26 \\
\text { healthy controls. } \\
\text { The second } \\
\text { cohort was } 16 \\
\text { patients } \\
\text { diagnosed with } \\
\text { MDD. }\end{array}$ & $\begin{array}{l}\text { The volume of the nucleus } \\
\text { accumbens (NA) was altered } \\
\text { in MDD patients, while } \\
\text { hippocampal formation (HF) } \\
\text { volume was increased } \\
\text { following ketamine in MDD } \\
\text { patients who exhibited } \\
\text { remission. }\end{array}$ & $\begin{array}{l}1 \mathrm{H}- \\
\text { MRS }\end{array}$ & 28272497 \\
\hline $\begin{array}{l}\text { Persistent antidepressant effect of low } \\
\text { dose ketamine } \\
\text { and activation in } \\
\text { the supplementary motor } \\
\text { area and anterior cingulate cortex in tre } \\
\text { atment-resistant depression: } \\
\text { A randomized control study }\end{array}$ & $\begin{array}{l}24 \text { patients } \\
\text { diagnosed with } \\
\text { TRD }\end{array}$ & $\begin{array}{l}\text { TRD patients receiving the } \\
0.5 \mathrm{mg} / \mathrm{kg} \text { ketamine infusion } \\
\text { exhibited activation in } \\
\text { supplementary } \\
\text { motor area (SMA) and } \\
\text { anterior cingulate cortex } \\
\text { (ACC) than did those } \\
\text { receiving the } \\
0.2 \mathrm{mg} / \mathrm{kg} \text { ketamine infusion. } \\
\text { The increase in the SUV in } \\
\text { the ACC was negatively } \\
\text { correlated with depressive } \\
\text { symptoms } \\
\text { after ketamine infusion. }\end{array}$ & PET & 28922734 \\
\hline $\begin{array}{l}\text { Glutamate levels and resting cerebral } \\
\text { blood flow in anterior cingulate cortex } \\
\text { are associated at rest and immediately } \\
\text { following infusion of S-ketamine in } \\
\text { healthy volunteers }\end{array}$ & $\begin{array}{l}25 \text { healthy } \\
\text { controls }\end{array}$ & $\begin{array}{l}\text { Dorsomedial prefrontal } \\
\text { cortex (PFC) and anterior } \\
\text { cingulate cortex (ACC). }\end{array}$ & $\begin{array}{l}1 \mathrm{H}- \\
\text { MRS }\end{array}$ & 29467681 \\
\hline $\begin{array}{l}\text { Default mode connectivity in } \\
\text { major depressive disorder } \\
\text { measured up to } 10 \text { days after ketamine } \\
\text { administration }\end{array}$ & $\begin{array}{l}33 \text { patients } \\
\text { diagnosed with } \\
\text { MDD and } 25 \\
\text { healthy controls } \\
\text { in a cross-over } \\
\text { study }\end{array}$ & $\begin{array}{l}\text { MDD patients exhibited } \\
\text { normalization of connectivity } \\
\text { between the insular cortex } \\
\text { (IC), posterior anterior } \\
\text { cingulate cortex (pACC) and } \\
\text { subgenual anterior cingulate } \\
\text { cortex (sgACC). }\end{array}$ & fMRI & 29580569 \\
\hline $\begin{array}{l}\text { 7T } 1 \text { H-MRS in major depressive } \\
\text { disorder: A Ketamine Treatment Study }\end{array}$ & $\begin{array}{l}17 \text { healthy } \\
\text { controls and } 20 \\
\text { patients } \\
\text { diagnosed with } \\
\text { MDD }\end{array}$ & $\begin{array}{l}\text { Different MDD phenotypes } \\
\text { exhibited different brain } \\
\text { region alterations following } \\
\text { ketamine infusions, ranging } \\
\text { from sub-geniculate anterior } \\
\text { cingulate cortex (ACC) to } \\
\text { anterior caudate (AC). }\end{array}$ & $\begin{array}{l}1 \mathrm{H}- \\
\text { MRS }\end{array}$ & 29748628 \\
\hline $\begin{array}{l}\text { Pharmacological fMRI: Effects of sub- } \\
\text { anesthetic ketamine on resting-state } \\
\text { functional connectivity in the default } \\
\text { mode network, salience network, dorsal } \\
\text { attention network and executive control } \\
\text { network }\end{array}$ & $\begin{array}{l}17 \text { healthy male } \\
\text { subjects }\end{array}$ & $\begin{array}{l}\text { Anterior cingulate cortex } \\
\text { (ACC), superior frontal gyrus } \\
\text { including supplementary } \\
\text { motor area (SMA), amygdala } \\
\text { (AMY), hippocampal } \\
\text { formation (HF), anterior } \\
\text { caudate (AC), nucleus } \\
\text { accumbens (NA), prefrontal } \\
\text { cortex (PFC). }\end{array}$ & $\begin{array}{l}\text { rs- } \\
\text { fcMRI }\end{array}$ & 30003027 \\
\hline $\begin{array}{l}\text { Ketamine, but Not the NMDAR } \\
\text { antagonist Lanicemine, Increases } \\
\text { prefrontal global connectivity in } \\
\text { depressed patients }\end{array}$ & $\begin{array}{l}56 \text { un-medicated } \\
\text { patients } \\
\text { diagnosed with } \\
\text { MDD }\end{array}$ & $\begin{array}{l}\text { Ketamine increased global } \\
\text { connectivity of the prefrontal } \\
\text { cortex (PFC) in depressed } \\
\text { patients. }\end{array}$ & fMRI & 30263977 \\
\hline
\end{tabular}


bioRxiv preprint doi: https://doi.org/10.1101/2020.04.28.053587; this version posted April 30, 2020. The copyright holder for this preprint (which was not certified by peer review) is the author/funder, who has granted bioRxiv a license to display the preprint in perpetuity. It is made available under aCC-BY-NC-ND 4.0 International license.

\begin{tabular}{|l|l|l|l|l|}
\hline $\begin{array}{l}\text { Functional connectivity between } \\
\text { prefrontal cortex and Subgenual } \\
\text { cingulate predicts antidepressant } \\
\text { effects of ketamine }\end{array}$ & $\begin{array}{l}\text { 24 patients } \\
\text { diagnosed with } \\
\text { MDD }\end{array}$ & $\begin{array}{l}\text { A single sub-anesthetic dose } \\
\text { of ketamine increased } \\
\text { functional connectivity } \\
\text { between prefrontal Cortex } \\
\text { (PFC) and the subgenual } \\
\text { anterior cingulate cortex } \\
\text { (sgACC). }\end{array}$ & $\begin{array}{l}\text { rs- } \\
\text { fcMRI }\end{array}$ & 30819549 \\
\hline NEGATIVE RESULTS & PARTICIPANTS & $\begin{array}{l}\text { KETAMINE'S SITE(S) } \\
\text { OF ACTION }\end{array}$ & MOD. & PMID \\
\hline TITLE & $\begin{array}{l}\text { Rapid (1 hour) and } \\
\text { sustained (7 days) } \\
\text { antidepressant effects } \\
\text { produced by ketamine } \\
\text { were not associated with } \\
\text { changes in amino acid } \\
\text { neurotransmitter content } \\
\text { in occipital cortex (OC). }\end{array}$ & 1H- & MRS & 21232924 \\
\hline $\begin{array}{l}\text { The antidepressant effect of ketamine is } \\
\text { not associated with changes in occipital } \\
\text { amino acid neurotransmitter content as } \\
\text { measured by ['H]-MRS }\end{array}$ & $\begin{array}{l}10 \text { patients diagnosed } \\
\text { with MDD }\end{array}$ &
\end{tabular}

\section{Neuroimaging modalities (MOD.):}

1H-MRS: 4-T 1H proton magnetic resonance spectroscopy

fMRI: Functional magnetic resonance imaging.

MEG: Magnetoencephalography;

PET: FDG positron emission tomography;

phMRI; Pharmacological magnetic resonance imaging.

rs-fcMRI: resting-state functional connectivity magnetic resonance imaging. 
bioRxiv preprint doi: https://doi.org/10.1101/2020.04.28.053587; this version posted April 30, 2020. The copyright holder for this preprint (which was not certified by peer review) is the author/funder, who has granted bioRxiv a license to display the preprint in perpetuity. It is made available under aCC-BY-NC-ND 4.0 International license.

Supplementary Table 2A. Gene symbols, ketamine glutamate receptor sub-network

\begin{tabular}{|c|c|c|c|}
\hline Gene symbol & Gene name (HGNC) & Location & Protein product \\
\hline ACHE & acetylcholinesterase (Cartwright blood group) & Plasma Membrane & enzyme \\
\hline ATF7IP & activating transcription factor 7 interacting protein & Nucleus & transcription regulator \\
\hline ATF7IP2 & activating transcription factor 7 interacting protein 2 & Nucleus & other \\
\hline ATP1A1 & ATPase $\mathrm{Na}+/ \mathrm{K}+$ transporting subunit alpha 1 & Plasma Membrane & transporter \\
\hline BORCS7 & BLOC-1 related complex subunit 7 & Cytoplasm & other \\
\hline BRD4 & bromodomain containing 4 & Nucleus & kinase \\
\hline CACNA1C & calcium voltage-gated channel subunit alpha1 C & Plasma Membrane & ion channel \\
\hline CACNB1 & calcium voltage-gated channel auxiliary subunit beta 1 & Plasma Membrane & ion channel \\
\hline CACNB2 & calcium voltage-gated channel auxiliary subunit beta 2 & Plasma Membrane & ion channel \\
\hline CACNG2 & calcium voltage-gated channel auxiliary subunit gamma 2 & Plasma Membrane & ion channel \\
\hline CHRM2 & cholinergic receptor muscarinic 2 & Plasma Membrane & G-protein coupled receptor \\
\hline CHRNA3 & cholinergic receptor nicotinic alpha 3 subunit & Plasma Membrane & transmembrane receptor \\
\hline CHRNA5 & cholinergic receptor nicotinic alpha 5 subunit & Plasma Membrane & transmembrane receptor \\
\hline CHRNA7 & cholinergic receptor nicotinic alpha 7 subunit & Plasma Membrane & transmembrane receptor \\
\hline CNR1 & cannabinoid receptor 1 & Plasma Membrane & G-protein coupled receptor \\
\hline DLG3 & discs large MAGUK scaffold protein 3 & Plasma Membrane & kinase \\
\hline DLG4 & discs large MAGUK scaffold protein 4 & Plasma Membrane & kinase \\
\hline DNMT1 & DNA methyltransferase 1 & Nucleus & enzyme \\
\hline EHMT1 & euchromatic histone lysine methyltransferase 1 & Nucleus & transcription regulator \\
\hline GABRA2 & gamma-aminobutyric acid type $A$ receptor alpha2 subunit & Plasma Membrane & ion channel \\
\hline GABRA5 & gamma-aminobutyric acid type $A$ receptor alpha5 subunit & Plasma Membrane & ion channel \\
\hline GAD1 & glutamate decarboxylase 1 & Cytoplasm & enzyme \\
\hline GLRA1 & glycine receptor alpha 1 & Plasma Membrane & ion channel \\
\hline GLRA2 & glycine receptor alpha 2 & Plasma Membrane & ion channel \\
\hline GLRB & glycine receptor beta & Plasma Membrane & ion channel \\
\hline GRIA1 & glutamate ionotropic receptor AMPA type subunit 1 & Plasma Membrane & ion channel \\
\hline GRIA2 & glutamate ionotropic receptor AMPA type subunit 2 & Plasma Membrane & ion channel \\
\hline GRIA4 & glutamate ionotropic receptor AMPA type subunit 4 & Plasma Membrane & ion channel \\
\hline GRIN1 & glutamate ionotropic receptor NMDA type subunit 1 & Plasma Membrane & ion channel \\
\hline GRIN2A & glutamate ionotropic receptor NMDA type subunit $2 \mathrm{~A}$ & Plasma Membrane & ion channel \\
\hline GRIN2B & glutamate ionotropic receptor NMDA type subunit 2B & Plasma Membrane & ion channel \\
\hline GRIN2C & glutamate ionotropic receptor NMDA type subunit $2 \mathrm{C}$ & Plasma Membrane & ion channel \\
\hline GRIN2D & glutamate ionotropic receptor NMDA type subunit 2D & Plasma Membrane & ion channel \\
\hline GRIN3A & glutamate ionotropic receptor NMDA type subunit $3 \mathrm{~A}$ & Plasma Membrane & ion channel \\
\hline GRIN3B & glutamate ionotropic receptor NMDA type subunit 3B & Plasma Membrane & ion channel \\
\hline HCN1 & hyperpolarization activated cyclic nucleotide gated potassium channel 1 & Plasma Membrane & ion channel \\
\hline HDAC5 & histone deacetylase 5 & Nucleus & transcription regulator \\
\hline MBD1 & methyl-CpG binding domain protein 1 & Nucleus & transcription regulator \\
\hline MPHOSPH8 & M-phase phosphoprotein 8 & Nucleus & transcription regulator \\
\hline NCAM1 & neural cell adhesion molecule 1 & Plasma Membrane & other \\
\hline NOS1 & nitric oxide synthase 1 & Cytoplasm & enzyme \\
\hline NOS2 & nitric oxide synthase 2 & Cytoplasm & enzyme \\
\hline NOS3 & nitric oxide synthase 3 & Cytoplasm & enzyme \\
\hline NQO1 & $\mathrm{NAD}(\mathrm{P}) \mathrm{H}$ quinone dehydrogenase 1 & Cytoplasm & enzyme \\
\hline OPRK1 & opioid receptor kappa 1 & Plasma Membrane & G-protein coupled receptor \\
\hline OPRM1 & opioid receptor mu 1 & Plasma Membrane & G-protein coupled receptor \\
\hline ROBO2 & roundabout guidance receptor 2 & Plasma Membrane & transmembrane receptor \\
\hline SETDB1 & SET domain bifurcated histone lysine methyltransferase 1 & Nucleus & enzyme \\
\hline SHANK2 & SH3 and multiple ankyrin repeat domains 2 & Plasma Membrane & other \\
\hline SIGMAR1 & sigma non-opioid intracellular receptor 1 & Plasma Membrane & transmembrane receptor \\
\hline SLC6A9 & solute carrier family 6 member 9 & Plasma Membrane & transporter \\
\hline TASOR & transcription activation suppressor & Nucleus & other \\
\hline TOGARAM2 & TOG array regulator of axonemal microtubules 2 & Other & other \\
\hline TRIM28 & tripartite motif containing 28 & Nucleus & transcription regulator \\
\hline ZNF274 & zinc finger protein 274 & Nucleus & transcription regulator \\
\hline
\end{tabular}


bioRxiv preprint doi: https://doi.org/10.1101/2020.04.28.053587; this version posted April 30, 2020. The copyright holder for this preprint (which was not certified by peer review) is the author/funder, who has granted bioRxiv a license to display the preprint in perpetuity. It is made available under aCC-BY-NC-ND 4.0 International license.

Supplementary Table 2B. Gene symbols, ketamine neuroplasticity sub-network

\begin{tabular}{|c|c|c|c|}
\hline Gene symbol & Gene name (HGNC) & Location & Protein product \\
\hline$A R C$ & activity regulated cytoskeleton associated protein & Cytoplasm & other \\
\hline ASCL1 & achaete-scute family bHLH transcription factor 1 & Nucleus & transcription regulator \\
\hline$B D N F$ & brain derived neurotrophic factor & Extracellular Space & growth factor \\
\hline$B D N F-A S$ & BDNF antisense RNA & Other & other \\
\hline CAMK2A & calcium/calmodulin dependent protein kinase II alpha & Cytoplasm & kinase \\
\hline CDKN1A & cyclin dependent kinase inhibitor $1 \mathrm{~A}$ & Nucleus & kinase \\
\hline CREM & CAMP responsive element modulator & Nucleus & transcription regulator \\
\hline CUX2 & cut like homeobox 2 & Nucleus & transcription regulator \\
\hline$D C C$ & DCC netrin 1 receptor & Plasma Membrane & transmembrane receptor \\
\hline DRD2 & dopamine receptor $\mathrm{D} 2$ & Plasma Membrane & G-protein coupled receptor \\
\hline EEF2K & eukaryotic elongation factor 2 kinase & Cytoplasm & kinase \\
\hline FMR1 & fragile $\mathrm{X}$ mental retardation 1 & Cytoplasm & translation regulator \\
\hline GDAP1L1 & ganglioside induced differentiation associated protein 1 like 1 & Other & other \\
\hline GRM5 & glutamate metabotropic receptor 5 & Plasma Membrane & G-protein coupled receptor \\
\hline HOMER1 & homer scaffold protein 1 & Plasma Membrane & other \\
\hline HTR1B & 5-hydroxytryptamine receptor 1B & Plasma Membrane & G-protein coupled receptor \\
\hline HTR2A & 5-hydroxytryptamine receptor $2 \mathrm{~A}$ & Plasma Membrane & G-protein coupled receptor \\
\hline KLF6 & Kruppel like factor 6 & Nucleus & transcription regulator \\
\hline LIN7C & lin-7 homolog $\mathrm{C}$, crumbs cell polarity complex component & Cytoplasm & other \\
\hline ENSG00000251574 & & Nucleus & RNA gene \\
\hline MEF2D & myocyte enhancer factor 2D & Nucleus & transcription regulator \\
\hline MYO6 & myosin VI & Cytoplasm & other \\
\hline MYT1L & myelin transcription factor 1 like & Nucleus & transcription regulator \\
\hline NEUROD1 & neuronal differentiation 1 & Nucleus & transcription regulator \\
\hline NEUROD2 & neuronal differentiation 2 & Nucleus & transcription regulator \\
\hline $\mathrm{NHLH} 2$ & nescient helix-loop-helix 2 & Nucleus & transcription regulator \\
\hline$N M B$ & neuromedin B & Extracellular Space & other \\
\hline NSMF & NMDA receptor synaptonuclear signaling and neuronal migration factor & Extracellular Space & other \\
\hline NTRK2 & neurotrophic receptor tyrosine kinase 2 & Plasma Membrane & kinase \\
\hline PTEN & phosphatase and tensin homolog & Cytoplasm & phosphatase \\
\hline PTGS2 & prostaglandin-endoperoxide synthase 2 & Cytoplasm & enzyme \\
\hline RAC1 & Rac family small GTPase 1 & Plasma Membrane & enzyme \\
\hline RASGRF2 & Ras protein specific guanine nucleotide releasing factor 2 & Cytoplasm & other \\
\hline RHOA & ras homolog family member $\mathrm{A}$ & Cytoplasm & enzyme \\
\hline $\mathrm{ROBO} 2$ & roundabout guidance receptor 2 & Plasma Membrane & transmembrane receptor \\
\hline ENSG00000225960 & & Nucleus & RNA gene \\
\hline SEMA3A & semaphorin $3 \mathrm{~A}$ & Extracellular Space & other \\
\hline SHANK1 & SH3 and multiple ankyrin repeat domains 1 & Cytoplasm & other \\
\hline SHANK2 & SH3 and multiple ankyrin repeat domains 2 & Plasma Membrane & other \\
\hline SHANK3 & $\mathrm{SH} 3$ and multiple ankyrin repeat domains 3 & Plasma Membrane & other \\
\hline$S L C 22 A 15$ & solute carrier family 22 member 15 & Other & transporter \\
\hline SLC6A2 & solute carrier family 6 member 2 & Plasma Membrane & transporter \\
\hline SLIT1 & slit guidance ligand 1 & Extracellular Space & other \\
\hline SLIT2 & slit guidance ligand 2 & Extracellular Space & other \\
\hline SNAP25 & synaptosome associated protein 25 & Plasma Membrane & transporter \\
\hline SYN1 & synapsin I & Plasma Membrane & transporter \\
\hline SYN2 & synapsin II & Plasma Membrane & other \\
\hline SYT3 & synaptotagmin 3 & Cytoplasm & transporter \\
\hline TBR1 & T-box, brain 1 & Nucleus & transcription regulator \\
\hline TCF4 & transcription factor 4 & Nucleus & transcription regulator \\
\hline
\end{tabular}

Supplementary Table 2C. Gene symbols, ketamine pharmacokinetic receptor sub-network

\begin{tabular}{|l|l|l|l|}
\hline Gene symbol & Gene name (HGNC) & Location & Protein product \\
\hline ANAPC2 & anaphase promoting complex subunit 2 & Nucleus \\
\hline CYP2A6 & cytochrome P450 family 2 subfamily A member 6 & Cytoplasm \\
\hline CYP2B6 & cytochrome P450 family 2 subfamily B member 6 & Cytoplasm \\
\hline CYP3A4 & cytochrome P450 family 3 subfamily A member 4 & Cytoplasm & enzyme \\
\hline ESR1 & estrogen receptor 1 & Nucleus & enzyme \\
\hline TCERG1 & transcription elongation regulator 1 & Nucleus & ligand-dependent nuclear receptor \\
\hline
\end{tabular}


bioRxiv preprint doi: https://doi.org/10.1101/2020.04.28.053587; this version posted April 30, 2020. The copyright holder for this preprint (which was not certified by peer review) is the author/funder, who has granted bioRxiv a license to display the preprint in perpetuity. It is made available under aCC-BY-NC-ND 4.0 International license.

\begin{tabular}{|c|c|c|c|c|}
\hline TARGET & SPECIES & $\begin{array}{l}\text { BINDING AFFINITY / INHIBITION } \\
\text { CONSTANT }\end{array}$ & STEREOSELECTIVITY & PMID \\
\hline $\begin{array}{l}\text { AMPAR: } \\
\text { GRIA1, } \\
\text { GRIA2, } \\
\text { GRIA4 }\end{array}$ & Human & $K_{i}=7 \pm 0.5 \mu \mathrm{M}(\mathrm{SK}), 24.5 \pm 2.0 \mu \mathrm{M}(\mathrm{RK})$ & SK has 3.5 -fold affinity of RK & 29945898 \\
\hline $\begin{array}{l}\text { NMDAR: } \\
\text { GRIN1, } \\
\text { GRIN2A, } \\
\text { GRIN2B, } \\
\text { GRIN2C, } \\
\text { GRIN2D, } \\
\text { GRIN3A, } \\
\text { GRIN3B }\end{array}$ & Human & $K_{i}=0.7 \pm 0.3 \mu \mathrm{M}(\mathrm{SK}), 2.3 \pm 0.3 \mu \mathrm{M}(\mathrm{RK})$ & SK has 3-fold affinity of RK & 29945898 \\
\hline $\begin{array}{l}\text { NMDAR: } \\
\text { GRIN1, } \\
\text { GRIN2A, } \\
\text { GRIN2B, } \\
\text { GRIN2C, } \\
\text { GRIN2D, } \\
\text { GRIN3A, } \\
\text { GRIN3B }\end{array}$ & Human & $K_{i}=0.06 \pm 0.1 \mu \mathrm{M}$ & Not measured & 1311263 \\
\hline CACNA1C & Rat & $I C_{50}=9.2 \mu \mathrm{M}$ & Not measured & 29945898 \\
\hline CHRM2 & Human & $K_{i}=7.4 \pm 4.5 \mu \mathrm{M}$ & No observed difference & 29945898 \\
\hline CNR1 & Human & $K_{i}=42 \pm 5 \mu \mathrm{M}$ & Not measured & 24093505 \\
\hline CHRNA3 & Human & $I C_{50}=50 \mu \mathrm{M}$ & Not measured & 29945898 \\
\hline CHRNA5 & Human & $I C_{50}=5 \mu \mathrm{M}$ & Not measured & 29945898 \\
\hline CHRNA7 & Human & $K_{i}=12 \pm 0.8 \mu \mathrm{M}$ & No observed difference & 29945898 \\
\hline DRD2 & Human & $K_{i}=12 \pm 0.8 \mu \mathrm{M}$ & Not measured & 12232776 \\
\hline DRD2 & Rat & $K_{i}=1 \pm 0.2 \mu \mathrm{M}$ & Not measured & 30034974 \\
\hline ESR1 & Human & $K_{i}=94 \pm 8 \mu \mathrm{M}$ & No observed difference & 29945898 \\
\hline GABRA1 & Human & $K_{i}=134 \pm 29 \mu \mathrm{M}$ & Not measured & 29945898 \\
\hline GABBR1 & Human & $K_{i}=144 \pm 32 \mu \mathrm{M}$ & Not measured & 29945898 \\
\hline GABRA2 & Guinea pig & $K_{i}=1 \pm 0.7 \mu \mathrm{M}(\mathrm{RK}), 12.2 \pm 1.2 \mu \mathrm{M}(\mathrm{SK})$ & RK has 12 -fold affinity of SK & 29945898 \\
\hline GABRA5 & Rat & $K_{i}=10 \pm 1.1 \mu \mathrm{M}$ & No observed difference & 29945898 \\
\hline GLRB & Human & $K_{i}=27 \pm 7.2 \mu \mathrm{M}$ & Not measured & 29945898 \\
\hline GRM5 & Rat & $K_{i}=7 \pm 0.62 \mu \mathrm{M}$ & Not measured & 30034974 \\
\hline HCN1 & $\begin{array}{l}\text { Rat PC12 } \\
\text { cells }\end{array}$ & $K_{i}=0.035 \pm 0.3 \mu \mathrm{M}(\mathrm{RK}), 54 \pm 3.7 \mu \mathrm{M}(\mathrm{SK})$ & RK has 5000 -fold affinity of SK & 29945898 \\
\hline HCN1 & Human & $E C_{50}=4.1 \mu \mathrm{M}-7.1 \mu \mathrm{M}(\mathrm{SK})$ & Not measured & 29945898 \\
\hline HTR3A & Human & $I C_{50}=910 \pm 30 \mu \mathrm{M}$ & Not measured & 10754635 \\
\hline HTR2A & Human & $K_{i}=19 \mu \mathrm{M}(\mathrm{RK}), 135 \mu \mathrm{M}(\mathrm{SK})$ & RK has 7-fold affinity of SK & 29945898 \\
\hline HTR1A & Human & $I C_{50}=46 \pm 1.4 \mu \mathrm{M}$ & Not measured & 29945898 \\
\hline HTR1B & Human & $K_{i}=6 \pm 0.2 \mu \mathrm{M}$ & Not measured & 29945898 \\
\hline OPRM1 & Guinea pig & $K_{i}=11 \mu \mathrm{M}(\mathrm{SK}), 28 \mu \mathrm{M}(\mathrm{RK})$ & $\begin{array}{l}\text { SK has } 2.5 \text {-fold affinity } \\
\text { of RK }\end{array}$ & 8835358 \\
\hline OPRD1 & Guinea pig & $K_{i}=130 \mu \mathrm{M}(\mathrm{SK}), 130 \quad \mu \mathrm{M}(\mathrm{RK})$ & No significant difference & 8835358 \\
\hline OPRK1 & $\mathrm{CHO}$ & $K_{i}=4.2 \pm 0.03 \mu \mathrm{M}(\mathrm{SK}), 4.6 \pm 0.04 \mu \mathrm{M}(\mathrm{RK})$ & No significant difference & 9915326 \\
\hline SIGMAR1 & Rat brain & $K_{i}=19 \mu \mathrm{M}(\mathrm{RK}), 200 \mu \mathrm{M}(\mathrm{SK})$ & RK has 10 -fold affinity of SK & 29945898 \\
\hline SLC6A2 & Human & $K_{i}=67 \pm 26 \mu \mathrm{M}$ & Not measured & 9523822 \\
\hline SLC6A3 & Human & $K_{i}=46.9 \mu \mathrm{M}(\mathrm{SK}), 390 \mu \mathrm{M}(\mathrm{RK})$ & SK has 8-fold affinity of RK & 10553955 \\
\hline SLC6A4 & Rat & $K_{i}=162 \pm 28 \mu \mathrm{M}$ & Not measured & 9523822 \\
\hline
\end{tabular}

Supplementary Table 3. Ketamine binding affinity studies. Affinity of ketamine to various CNS targets as measured by displacement of radiolabeled ligands or radioligand assays. Molecules in bold text were added to the ketamine network based on the high affinity binding of ketamine. CHO: Chinese hamster ovary cells; PubMed ID numbers refers to where the original studies can be found at the PubMed web site, National Library of Medicine (65). 
A
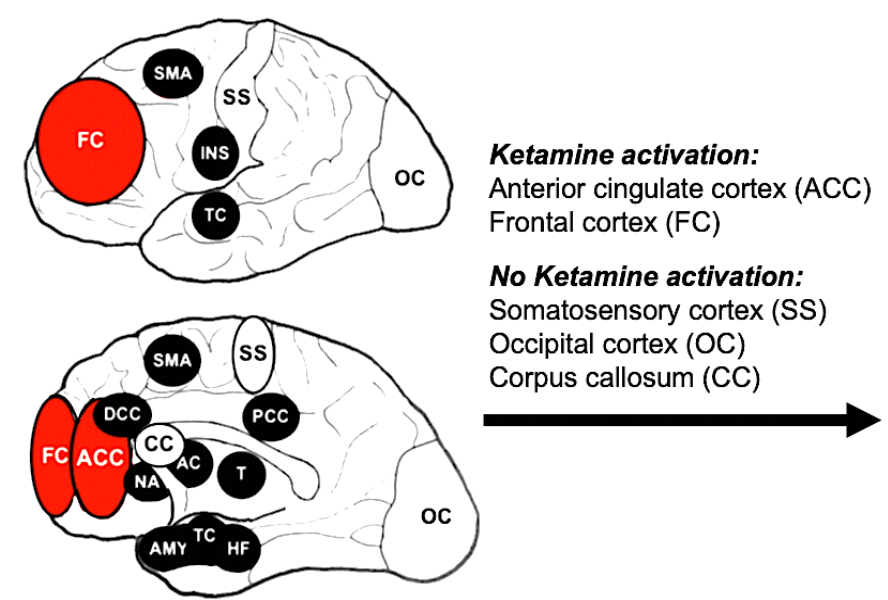

Ketamine activation:

Anterior cingulate cortex (ACC)

Frontal cortex (FC)

No Ketamine activation:

Somatosensory cortex (SS)

Occipital cortex (OC)

Corpus callosum (CC)

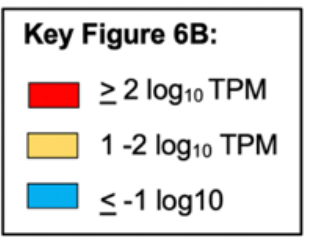

B

\begin{tabular}{|c|c|c|c|c|c|c|c|c|c|c|c|}
\hline GENES & ACC & FC & ss & oc & CC & GENES & ACC & FC & ss & OC & CC \\
\hline ACHE & & & & & & GRIN3A & & & & & \\
\hline ANAPC2 & & & & & & GRIN3B & & & & & \\
\hline ARC & & & & & & GRM5 & & & & & \\
\hline$A S C L 1$ & & & & & & HCN1 & & & & & \\
\hline ATF7IP & & & & & & HDAC5 & & & & & \\
\hline ATFZIP2 & & & & & & HOMER1 & & & & & \\
\hline ATP1A1 & & & & & & HTR1B & & & & & \\
\hline BDNF & & & & & & HTR2A & & & & & \\
\hline BORCS7 & & & & & & KLFG & & & & & \\
\hline BRD4 & & & & & & LIN7C & & & & & \\
\hline CACNA1C & & & & & & MBD1 & & & & & \\
\hline CACNB1 & & & & & & MEF2D & & & & & \\
\hline CACNB2 & & & & & & MYO6 & & & & & \\
\hline CACNG2 & & & & & & MYT1L & & & & & \\
\hline CAMK $2 A$ & & & & & & NCAM1 & & & & & \\
\hline CDKN1A & & & & & & NEUROD1 & & & & & \\
\hline CHRM2 & & & & & & NEUROD2 & & & & & \\
\hline CHRNA3 & & & & & & NHLLH2 & & & & & \\
\hline CHRNA5 & & & & & & NMB & & & & & \\
\hline CHRNA7 & & & & & & NOS1 & & & & & \\
\hline CNR1 & & & & & & NOS2 & & & & & \\
\hline CREM & & & & & & NOS3 & & & & & \\
\hline CUX2 & & & & & & NQO1 & & & & & \\
\hline CYP2A6 & & & & & & NSMF & & & & & \\
\hline CYP2B 6 & & & & & & NTRK2 & & & & & \\
\hline CYP $3 A 4$ & & & & & & OPRK1 & & & & & \\
\hline$D C C$ & & & & & & OPRM 1 & & & & & \\
\hline$D L G 3$ & & & & & & $R A C 1$ & & & & & \\
\hline DLG4 & & & & & & RASGRF2 & & & & & \\
\hline DNMT1 & & & & & & RHOA & & & & & \\
\hline$D R D 2$ & & & & & & ROBO2 & & & & & \\
\hline EEF2K & & & & & & SEMA3A & & & & & \\
\hline EHMT1 & & & & & & SETDB1 & & & & & \\
\hline ESR1 & & & & & & SHANK1 & & & & & \\
\hline FMR1 & & & & & & SHANK2 & & & & & \\
\hline GABRA2 & & & & & & SHANK3 & & & & & \\
\hline GABRA5 & & & & & & SIGMAR1 & & & & & \\
\hline GAD1 & & & & & & $S L C 6 A 2$ & & & & & \\
\hline GDAP1L1 & & & & & & SLC6A9 & & & & & \\
\hline GLRA1 & & & & & & SLIT1 & & & & & \\
\hline GLRA2 & & & & & & SLIT2 & & & & & \\
\hline$G L R B$ & & & & & & SNAP25 & & & & & \\
\hline GRIA1 & & & & & & SYN1 & & & & & \\
\hline GRIA2 & & & & & & SYN2 & & & & & \\
\hline GRIA4 & & & & & & SYT3 & & & & & \\
\hline GRIN1 & & & & & & TBR1 & & & & & \\
\hline GRIN2A & & & & & & TCERG1 & & & & & \\
\hline GRIN2B & & & & & & TCF4 & & & & & \\
\hline GRIN2C & & & & & & TRIM28 & & & & & \\
\hline GRIN2D & & & & & & ZNF274 & & & & & \\
\hline
\end{tabular}

Supplementary Fig. 1. Consensus between ketamine pharmacogenomic pathway gene expression in human brain and regions where ketamine exerts a rapid antidepressant effect derived from functional imaging studies (Supplementary Table 1). (A) Human brain regions impacted by ketamine projected onto lateral (top) and medial (bottom) surfaces of the brain. Black indicates ketamine activation regions and dark red indicates those CNS areas first activated by the drug. (B) Expression of 100 out of 107 genes in the ketamine pharmacogenomic pathway whose expression could be determined.

Abbreviations: ACC: Anterior cingulate cortex; AC: Anterior caudate; AMY: Amygdala; CC: Corpus callosum; dACC: Dorsal anterior cingulate cortex; FC: Frontal cortex; HF: Hippocampal formation; INS: Insular cortex; NA: Nucleus accumbens; OC: Occipital cortex; pCC: Posterior cingulate cortex; PFC: Prefrontal cortex; SMA: Supplementary motor area; Supplementary Figure 3. Examples of in situ hybridization of selected super-pathway genes that are ketamine PD targets, from the human brain atlas of the Allen Brain Science Institute (62) sgACC: Subgenual anterior cingulate cortex; SS:

Somatosensory cortex; T: Thalamus; TC: Temporal cortex; TPM: Transcripts per million. 
Supplementary Figure 2. Examples of in situ hybridization of selected super-pathway genes that are ketamine PD targets, from (62)

\section{Amygdala}

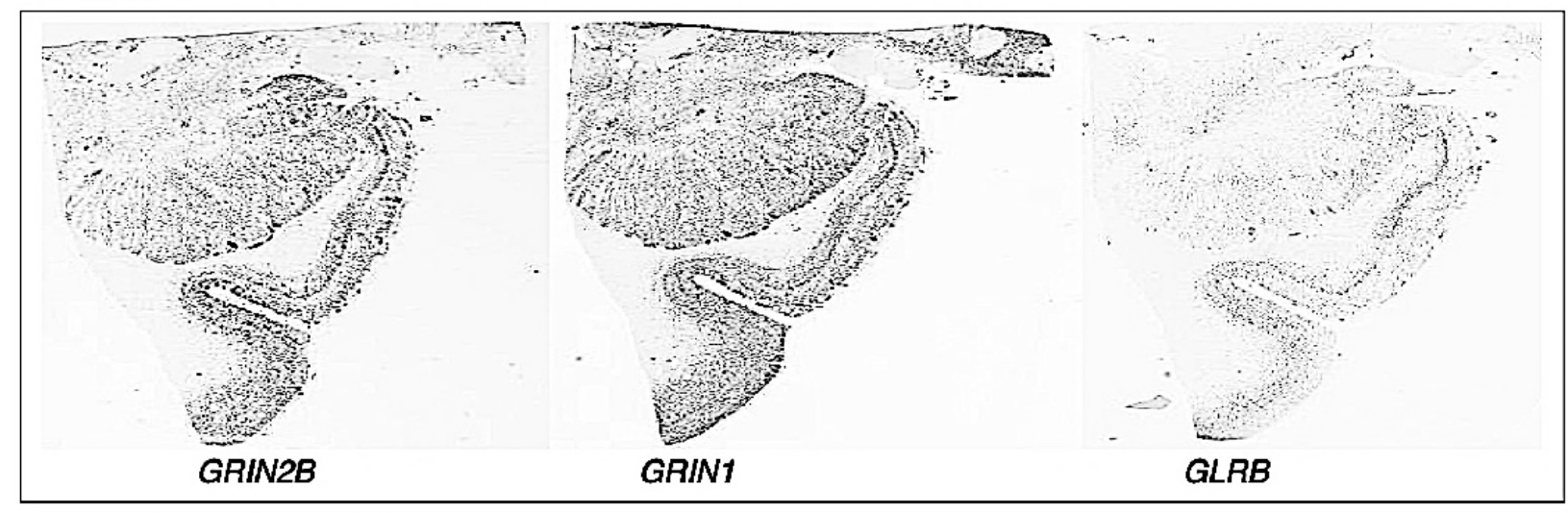

Hippocampal formation

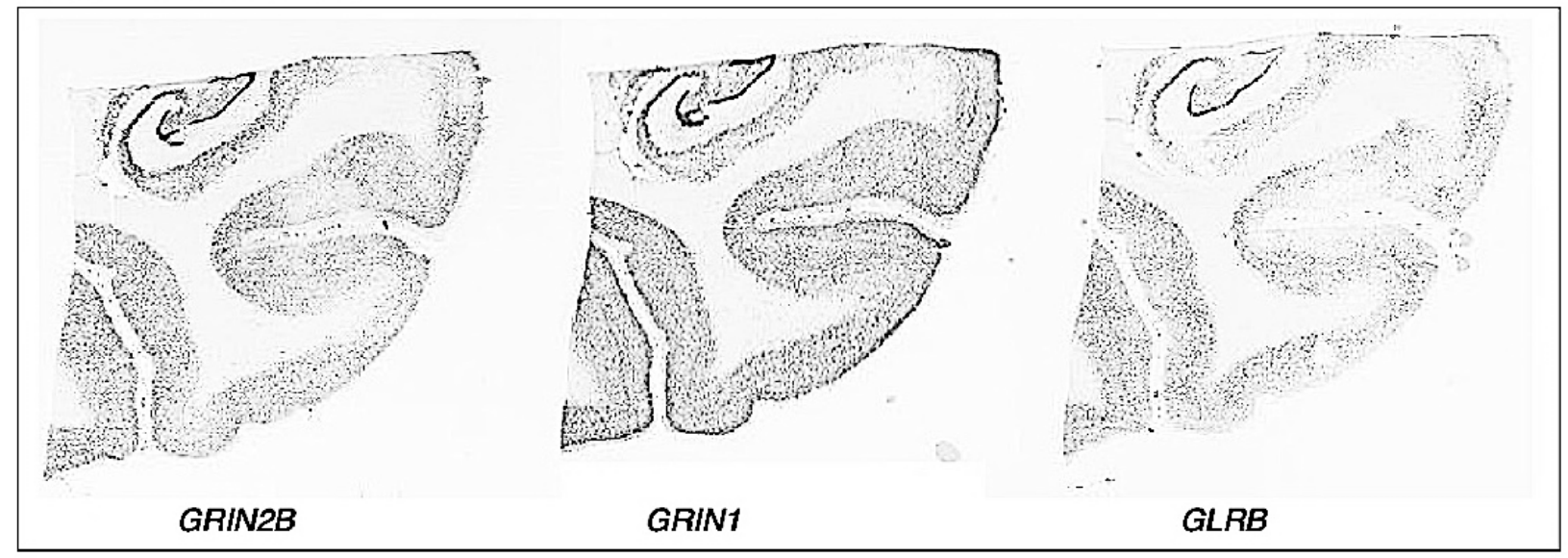

Anterior caudate (AC), nucleus accumbens (NA), putamen $(P)$ and globus pallidus

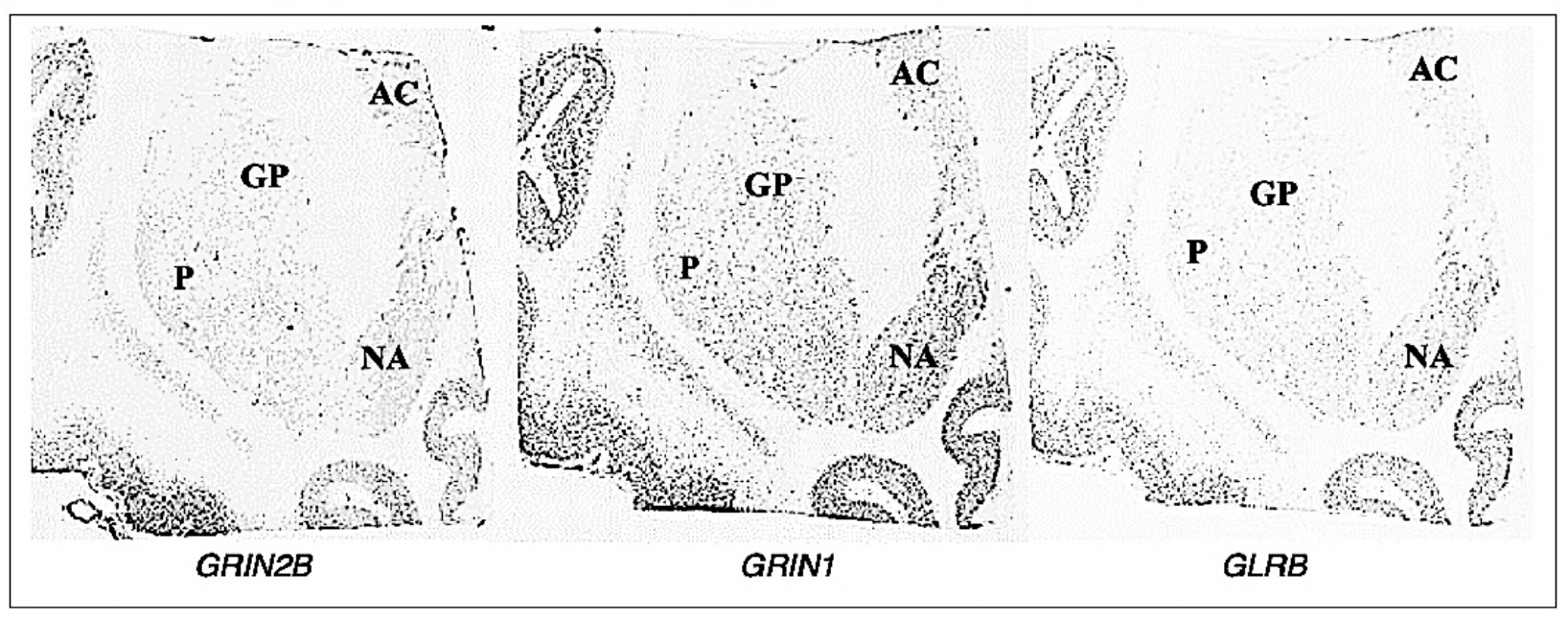


bioRxiv preprint doi: https://doi.org/10.1101/2020.04.28.053587; this version posted April 30, 2020. The copyright holder for this preprint (which was not certified by peer review) is the author/funder, who has granted bioRxiv a license to display the preprint in perpetuity. It is made available under aCC-BY-NC-ND 4.0 International license.

Supplementary Figure 2. Examples of in situ hybridization of selected super-pathway genes that are ketamine PD targets, from (62), continued

\section{Anterior cingulate cortex}

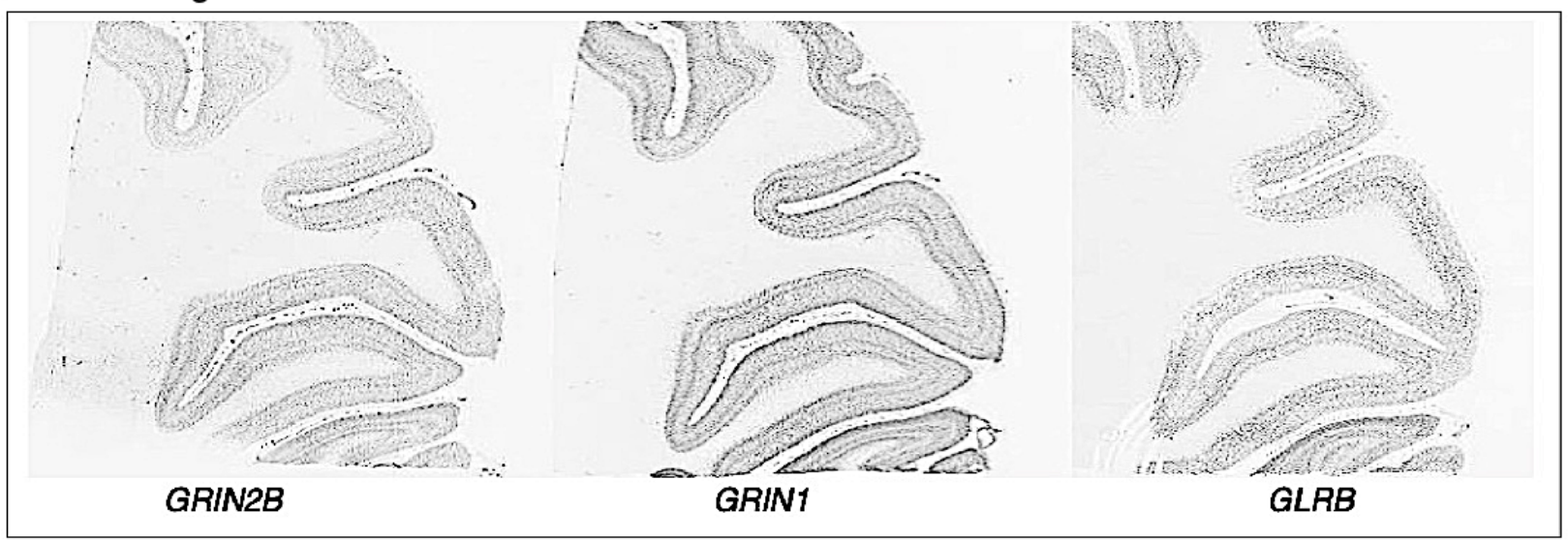

\section{Frontal cortex}

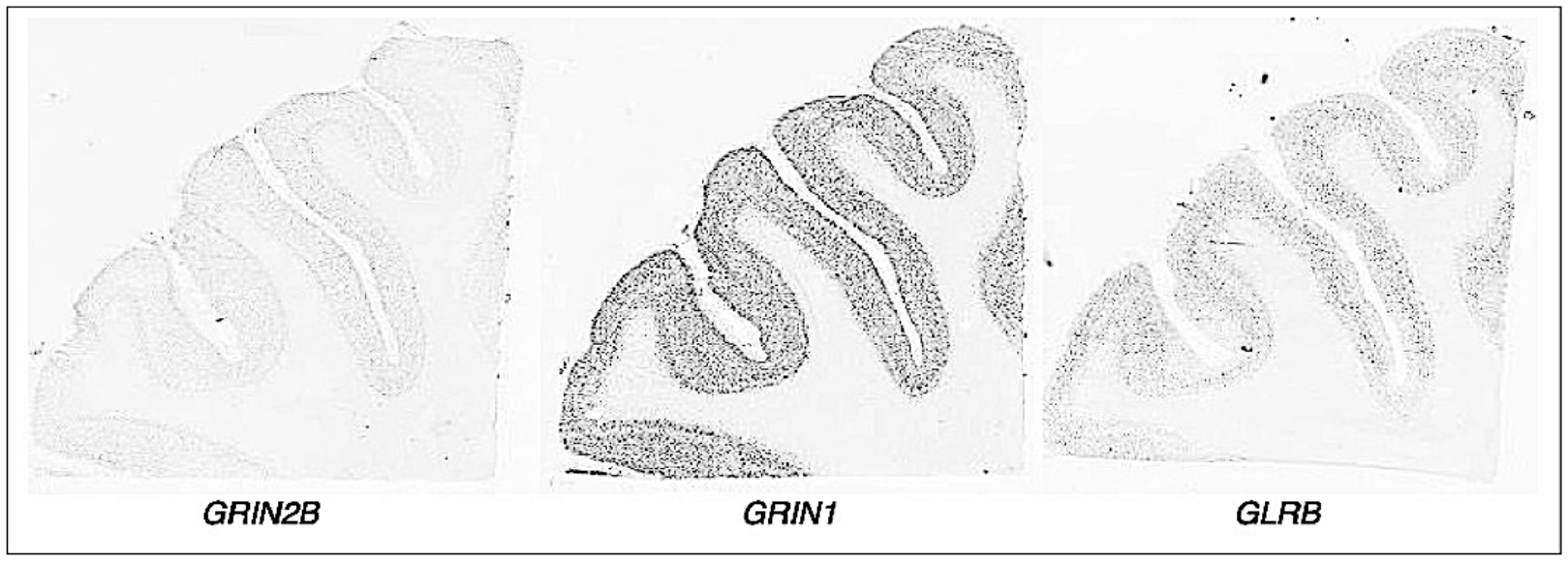

Dorsolateral prefrontal cortext

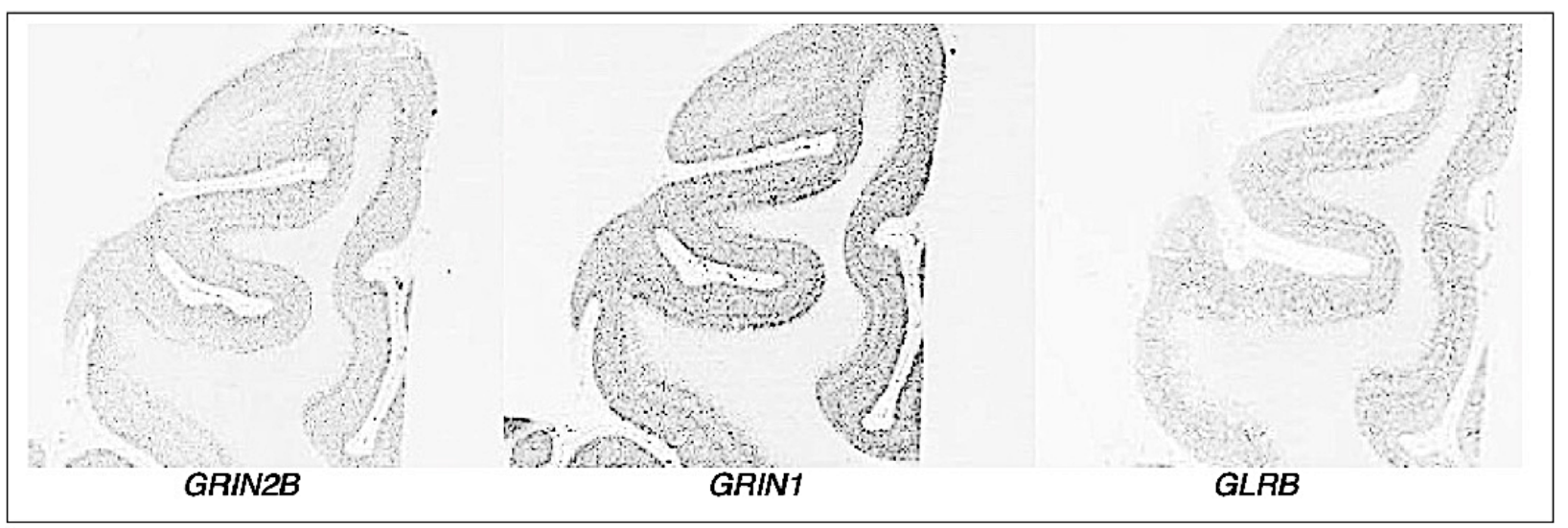


bioRxiv preprint doi: https://doi.org/10.1101/2020.04.28.053587; this version posted April 30, 2020. The copyright holder for this preprint (which

was not certified by peer review) is the author/funder, who has granted bioRxiv a license to display the preprint in perpetuity. It is made available under aCC-BY-NC-ND 4.0 International license.

\section{Additional Figure captions:}

Supplementary Figure 4. GWAS SNPs from the ketamine glutamate receptor sub-network

Supplementary Figure 5. GWAS SNPs from the ketamine neuroplasticity sub-network 